\title{
TENSILE PROPERTIES AND DEFORMATION-INDUCED TRANSFORMATIONS IN METASTABLE AUSTENITIC SINGLE CRYSTALS
}

Gerard Allen Goeser

(M. S. thesis)

December 1976

Prepared for the U. S. Energy Research and

Development Administration under Contract W-7405-ENG-48

\section{For Reference}

Not to be taken from this room

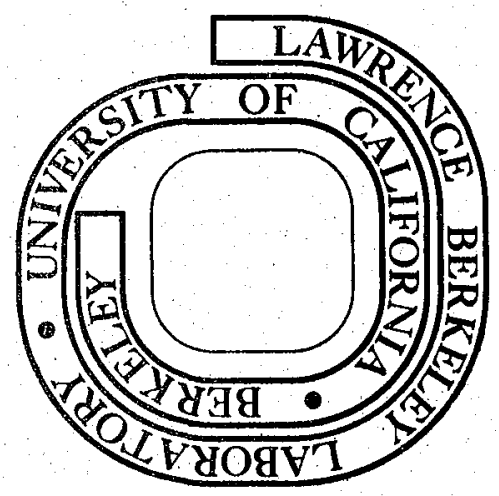


This report was prepared as an account of work sponsored by the United States Government. Neither the United States nor the United States Energy Research and Development Administration, nor any of their employees, nor any of their contractors, subcontractors, or their employees, makes any warranty, express or implied, or assumes any legal liability or responsibility for the accuracy, completeness or usefulness of any information, apparatus, product or process disclosed, or represents that its use would not infringe privately owned rights. 


\section{CONTENTS}

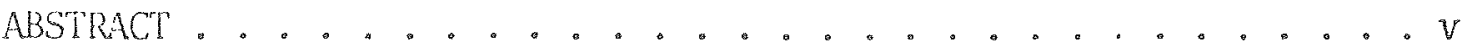

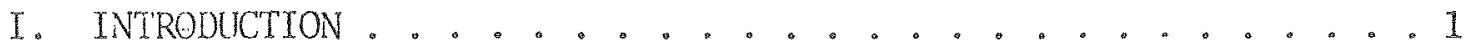

A. Experimental Objectives and Experimental Design...... 1

B. Crystallography of Strain-Induced Transfomations in

$\mathrm{Fe}-15 \mathrm{Cr}-15 \mathrm{vi} \ldots \ldots . . \ldots 3$

II. SPECIMEN PREPARATION ...................6

III. TMNSILE IESTS。 ......................8

IV. MAGETIC VOLUME-FRACTION MEASUREMENTS. . . . . . . . .11

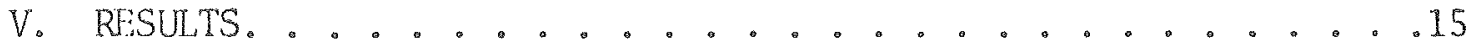

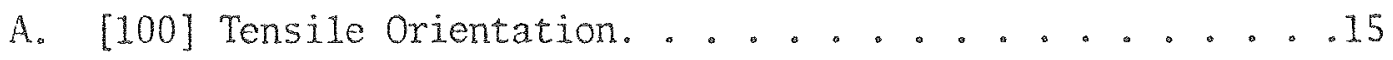

B. [123] Tensile Orientation. ............... . . . .

C. [112] Tensile Orientation. .................. . . . . .

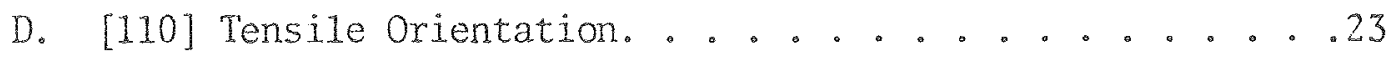

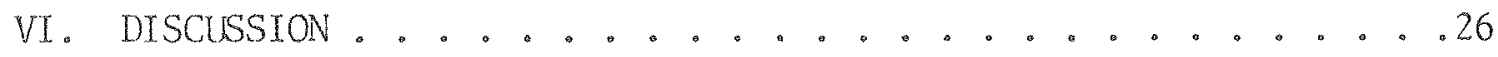

A. Ductility......................26

B. Yield Points...................... . . 27

C. Strain Hardening ................. 28

D. Effect of Tensile Orientation on Volume-Fraction of

Martensite...................30

VIY CONCLUSTONS. .....................35 


\section{Contents}

(continued)

ACKNOWLEGMETS ................. 36

TRPLES. . . . . . . . . . . . . . . 3

FIGURESS 。. . . . . . . . . . . . . . 40

REFEREICES. . . . . . . . . . . . . . . 58 
TENSILE PROPERTIES ANT DEFORMTION-INDUCED TRANSFORNATIONS

IN METASTABLE AUSTENTTIC SINGLE CRYSTALS

Gerard Allen Goeser

Major Subject: Naterials Science and Engineering, Physical Metallurgy

Materials and Molecular Research Division

Lawrence Berkeley Laboratory

University of Califormia

Berkeley, Califomia 94720

December 1976

\section{ABSTRACT}

Single crystal tensile specimens of Fe-15Cr-15Ni (wt. $\%$ ), a metastable austenite, have been made in four different tensile orientations and strained to fracture at two temperatures between $\mathrm{M}_{\mathrm{d}}$ and $\mathrm{M}_{\mathrm{S}}$. The amount of transformation to strain-induced bcc martensite which proceeds concurrently with plastic strain is recorded at each orientation.

The specimens tested at the lower temperature exhibit a higher strain-hardening rate and a much higher rate of transformation to martensite with strain than specimens of identical orientation strained at a temperature $80^{\circ} \mathrm{C}$ higher. The strain-hardening behavior of those specimens tested at the lower temperature, with significant martensitic txansformation occurring, is seen to be a combined effect of normal fcc, orientation-dependent strain-hardening behavior (as exhibited by the specimens tested at the upper temperature) and the superposition of strain-hardening behavior due to the presence of the harder martensitic phase. 
The effect of tensile orientation on the rate of transformation to strain-induced martensite as straining proceeds is found to be a function of the number of active slip planes in operation at a given orientation rather than to the resultant shear stresses and normal stresses on potential martensite habit planes.

The tensile orientations with the smaller number of active slip planes show a larger rate of transformation to strain-induced martensite as tensile deformation proceeds. 


\section{INTRODUCTION}

\section{A. Experimental Objectives and Experiment Design}

The object of this study is to determine the extent of a straininduced martensitic transformation in austenite single crystals, at various tensile orientations and to relate this to strain-hardening behavior of the crystals.

The crystals are of an austenitic TRIP alloy, Fe-15Cr-15Ni (wt.:). The stability of such an austenitic alloy against transformation to martensite is measured by $\mathrm{Ms}_{\alpha}$ and $\mathrm{Md}_{\alpha}$ temperatures. In the range of metastability between the upper temperature limit $\mathrm{Md}_{\alpha}$ and the lower temperature limit Ms the bec martensitic transformation will occur only upon plastic deformation. Below $\mathrm{Ms}_{\alpha}$, some isothermal martensitic transformation occurs, though plastic deformation below $\mathrm{Ms}_{\alpha}$ will cause further martensitic transformation. Above $M d a$, the bcc martensite will not occur despite the assistance of deformation. The Md $\alpha_{\alpha}$ temmerature varies with the crystallographic tensile orientation of a single-crystal specimen. ${ }^{1}$ The orientation dependence of the resolved shear stress on potential $\alpha$-martensite habit planes is thought to be the basis for the different values of $\mathrm{Md}_{\alpha}$ at different tensile orientations. ${ }^{9}$ For a given tensile orientation the amount of transformation to $\alpha$-martensite at a given level of strain will increase the further below $\mathrm{Md}_{\alpha}$ (and closer to $\mathrm{ws}_{\alpha}$ ) the plastic deformation occurs. 
Another strain-induced transformation, to an $\varepsilon$-hcp phase, also occurs only below a temperature $\mathrm{Md}_{\varepsilon}$, known to be greater than $300^{\circ} \mathrm{C}{ }^{1}$ Md is a higher temperature than $M d_{\alpha}$ for any tensile orientation, though an orientation dependence of $\mathrm{Md}$, has not been determined. The $\varepsilon$-hcp transformation in this alloy has only been observed in the context of plastic deformation, whether that deformation is a result of a mechanical straining process or is localized in the austenite in the vicinity of isothernal a-martensite.

In this study single-crystal specimens of four different tensile orientations have been strained to fracture at tenperatures in the metastable temperature range for the $\alpha$-martensite transformation. The crystallographic tensile axes are [100], [110], [112], and [123]. The extent of transformation to martensite (here meaning bec $\alpha$, unless otheruise indicated) at successively larger levels of strain was detcmined by a magnetic saturation method. The particular tensile orientations were chosen to activate different numbers of fcc slip systens in the deformation process. Normal stress along [100] tenside exis is resolved equally on eight $\{111\}-[110]$ slip systems, two on each of the four \{111\} slip planes. A [110] tensile axis will obtain the highest resolved shear stress on four $\{111\}-[110]$ slip systens, two on each of two \{111\} planes. A [112] tensile axis results in maximm resolved shear stress on two slip system, on intersecting slip planes. A [123] tensile axis has its highest resolved shear stress on one slip system only. It was intended that the possible effect of the number of active slip systems and slip planes on the extent of the concurrent martensitic transfomation could be examined in this way. 
Specimens of [110], [112], and [123] tensile axes were strained at two temperatures in the metastable range. The upper temperature was sufficientily close to $M{ }_{\alpha}$ so that the extent of strain-induced martensitic transformation would be quite small. Deformation at the lower testing temperature resulted in a much greater degree of bec transformation products. This afforded an opportunity to see if the differing extent of transformation to martensite due to the difference in temperature of deformation would be reflected in differences in the strain-hardening curves obtained at each temperature for a given tensile orientation.

\section{B. Crystallography of Strain-Induced Transformations}

$$
\text { in } \mathrm{Fe}-15 \mathrm{Cr}-15 \mathrm{Ni}
$$

A previous study ${ }^{1}$ of the strain-induced transformations in $\mathrm{Fe}-15 \mathrm{Cr}-15 \mathrm{Ni}$ has shown that the bcc martensite phase is acicular. The large aspect ratio of martensite needles suggests a description of the austenite natrix and martensite needles as a fibrous composite with discontinuous sibers. The long axis of a needle of martensite always lies in a \{111\} plane in which slip activity is present at the particular tensile prientation of a crystal. The needles lying in such a $\{111\}$ plane have directions approximating the three $<110\rangle$ directions in that plane. The needles are clustered within bands bounded by the associated \{111\} plane. These bands are confined between sheets of $\varepsilon$-hep phase occurring in the [111] slip plane. For a crystal with slip occurring on the (111)-[011] plane, the orientation relationships of the deformation-inouced transformation products are $(01,]_{\gamma} \|(2110)_{\varepsilon}$ and $[111]_{\gamma}\left\|[110]_{\alpha}\right\|[0001]_{\varepsilon}$ Individual needles in a $\{111\}$ plane are found in pairs joined in a bcc twin orientation. 
In single-slip tensile specinens strained to $\varepsilon_{\mathrm{p}}=.05^{\text {क }}$, below $\mathrm{M}$. Stone ${ }^{1}$ has observed the $\varepsilon$-hcp phase as continuous sheets on the active \{111\} plane, extending through the crystal in the slipped bands. These

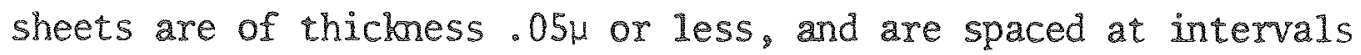
between about. $5 \mu$ to $2.5 \mu$. No investigation of the relationship between volume-fraction of $\varepsilon$-hcp phase and tensile strain or orientation has been made for Fe-15Cr-15Ni at higher strains than $\varepsilon_{\mathrm{p}}=.05$. Stone's data at $\varepsilon_{p}=.05$ shows that the volume-fraction of $\varepsilon$-hcp in a single-slip specimen varies little as defomation temperature is increased $(.021$ at $185^{\circ} \mathrm{K}, .025$ at $242^{\circ} \mathrm{K}, .020$ at $273^{\circ} \mathrm{K}$ ), in contrast to the strong temperature dependence of the tendency to bcc strain-induced transformation within the metastable temperature range. Tensile orientation also does not exhibit a significant effect on the amount of $\varepsilon$-hcp transformation at $\varepsilon_{p}=.05$. Guntner and Reed ${ }^{2}$ have observed a peak of E-hcp volume-fraction at $9 \%$ plastic strain in polycrystalline re-18Cr-9Ni, and a subsequent reduction to less than one third of peak value at a strain of $26 \%$. The question of whether the $\varepsilon$-hcp phase transforms to martensite or reverts to austenite at higher strains has been resolved in favor of the latter mechanism by Stone. Although it may be unsafe to extrapolate Stone's data on $\varepsilon$-hep to the higher strains involved in this study, it is reasonable to believe that the mechanical properties of the single-crystal specimens are primarily a function of normal tensile orientation effects and the related extent of transformation to bcc martensite at the various defomation temperatures. The E-hep phase serves to partition the austenite, and the clusters or martensite needles are bounded by parallel sheets of $\varepsilon$-hop on the 
plane(s) of slip and transformation. This limits the cross-sectional dimensions of the martensite needles in the $\varepsilon$-hcp/ $\alpha$ sandwich configuration. When multiple slip is occurring, the $\varepsilon$-hep sheets on an intersecting (111) slip plane may serve to limit the length (and perhaps the volumefraction) of $\alpha$ on the other active plane of transformation and slip which intersects these $\varepsilon$ whp sheets. Stone has observed by electron microscopy that a bec martensite needle is never observed to have punched through an $\varepsilon$-hcp sheet on an intersecting active slip plane.

The actual values of $\mathrm{M}_{\mathrm{d} \alpha}$ have not been determined for any tensile orientations of $\mathrm{Fe}-15 \mathrm{Cr}-15 \mathrm{Ni}$. While Stone has identified $190^{\circ} \mathrm{K}$ as $\mathrm{M}_{\mathrm{d} \alpha}$ for the [100] orientation, this is questionable except in a restricted sense. The $M_{\mathrm{d} \alpha}$ temperature is a function of stress as well as the relative stability of the austenite. Since a crystal strain-hardens, the bcc martensite may not be observed at lower strains (stresses) yet may be observed at higher strains (stresses). In this experiment several tensile orientations have been tested to necking stress at $-10^{\circ} \mathrm{C}$, or $20^{\circ} \mathrm{C}$ higher than the temperature at which Stone observed only $\varepsilon$-hcp phase and austenite in crystals of the same orientations strained to a maximum of $12 \%$ plastic strain. In this study, minute amounts of bcc martensite were observed in all specimens tested to necking stress at $-10^{\circ} \mathrm{C}$. It is evident that by an absolute definition of $M \mathrm{~d} \alpha$, (i.e., one not relative to tensile orientation or level of stress or strain that occurs) that temperature is above $-10^{\circ} \mathrm{C}$. The $\mathrm{M}_{s c}$ temperature of $\mathrm{Fe}-15 \mathrm{Cr}-15 \mathrm{Ni}$ is about $-140^{\circ} \mathrm{C}$, as determined by visual observation of a polished austenite specimen dipped in cooling baths of progressively lower temperatures until transformation occurred. 


\section{SPECTREN PREPARATION}

The single crystal from which 211 tensile specimens were cut was produced by the Materials Laboratory of Pratt and Whitney. It was a cylinder $6^{\prime \prime}$ long and $1.2^{\prime \prime}$ in diameter with a $<100>$ crystallographic direction about $6^{\circ}$ from the cylinder axis. The crystal was homogenized for five days at $1370^{\circ} \mathrm{C}, 50^{\circ}$ below the liquidus, in a helium atmosphere. This long, high-temperature homogenization was undertaken since a previous homogenization attempt at $1200^{\circ} \mathrm{C}$ for 3 days proved insufficient co eliminate small iron-rich regions with "dendrite" branches in $\langle 100\rangle$

directions. Although the wt. $\%$ difference in solute was less than 1: for each solute after the first homogenization, the strain-induced bce transfomation product was localized to the iron-rich regions only (Fig. 1). After the second homogenization, no such effect was observed. (100) and (111) slabs, 0.1" thick, were cut with a circular saw fron the cylinder after orientation of the crystal was checked using a back-reflection Laue diffraction pattem. From the (100) slabs, blanks of [110] and [100] tensile orientation were cut wits a smaller circular saw. From the (111) slabs, blanks of [123] and [112] tensile axes were cut. Final corrections of residual deviations from desired tensile orientations were achieved by hand-filing the surfaces of the blanks after further checking by back-reflection Laue diffraction pattem. Hand-filing also was used for the necessary reduction of specimen thickness and to reduce width in the gage. A maxinum thiclness of .050" was

This segregacion was retemined by electron microprobe analysis. 
required because of size restrictions of the search coil of the magnetic saturation measurement apparatus. Final dimensions of the tensile specimens are shown in Fig. 3. In all cases final tensile alignment was within $1^{\circ}$ of the desired orientation.

The final step of specimen preparation was electropolishing to give a mirror surface for later optical microscopy studies of slip lines and surface relief due to the intersection of martensite needles with the specimen surface. Electropolishing was carried out in a $15 \%$ perchloric$85 \%$ acetic acid solution with a stainless steel cathode. 


\section{TENSILE TESTS}

Tensile tests were nerfomed at $-10^{\circ} \mathrm{C}$ and $-92^{\circ} \mathrm{C}$ on a standard Instron machine at a crosshead speed on $.02 \mathrm{~cm} / \mathrm{min}(\dot{\varepsilon} \approx .013 / \mathrm{min})$. After carefully aligning, specimens were immersed in a constant temperature ethyl alcohol bath controlled by the addition of liquid nitrogen and monitored with a copper-constantan thermocouple. Two testing procedures were used. At the lower temperature of $-92^{\circ} \mathrm{C}$ specimens were pulled to fracture by incremental straining. Before each successive increment of plastic strain the specinen was removed from the bath for observation of the following:
a) cross-section and gage length
b) magnetic saturation
c) optical metallography of polished gage surface

For specimens pulled at the higher temperature, $-10^{\circ} \mathrm{C}$, a different testing program was used. Each specimen was strained to fracture without any interruptions of the straining process for measurement of crosssection, gage length, etc. For these specimens all plastic strain measurements were inferred from cross head velocity. The real stress corresponding to any level of strain in specinens tested at $-10^{\circ} \mathrm{C}$ was computed by dividing load by the cross-sectional area assumed from using the value of transverselaxial strain ratio that was observed at the same level of strain in the specimen of the same tensile orientation tested at the lower temperature. The transverse/axial strain ratio in these specimens was always within 3\% of .50, with the larger deviations occurring generally at the higher strains. 
Recorded values of the gage thickness of the specimens strained incrementally at $-92^{\circ} \mathrm{C}$ were taken as the average of a series of measurements along the length of the gage. The thickness measurements varied by as mch as $\pm 10 \%$ atrandon points along the uneven surface of the specinen's face resulting with higher strains at one of the orientations. The unevenness of the surface at higher strains was most severe by far in the case of the [100] orientation (Fig. 2). This was possibly due to large local variation in the distribution of slip activity between the various active $\{111\}-[110]$ slip systems, of which there was at least one on each \{111\} plane. As the gage thickness is much less than the gage width, this local variation in slip activity (and local shear direction and magnitude) would have been less likely to be balanced by compensating local activity on other slip systems and planes in adjacent regions of the crystal through the thickness than across its width. Accordingly, variations in specimen width (measured by optical micrometer) were not more than $2 \%$ at different points down the gage. Gage thickness and surface evenness were most uniform for those tensile orientations where slip was observed on one slip plane only (i.e., $[123],[110])$, about $\pm 2 \%$. An additional contribution to the error of cross-section measurenents was the romding of the edges of the rectangular gage cross-section. The statistical nature of thickness measurements was the largest factor in detemining the error bars at the data points on the strain-hardening curves of the low-temperature specimens. As the volume-fraction measurements of martensite by magnetic saturation also utilize cross-section data, they are subject to the same degree of error as the cross-section data. 
A specimen of [110] orientation was strained to fracture by increments at $-10^{\circ} \mathrm{C}$, in addition to the specimen of this orientation tested by uninterrupted straining at $-10^{\circ} \mathrm{C}$. 


\section{MAGNETIC VOLIME-FRACTION MEASUREMENTS}

In the austenitic state the alloy $\mathrm{Fe}-15 \mathrm{Cr}-15 \mathrm{Ni}$ is not ferromagnetic whereas in the bcc martensite phase it is ferromagnetic. The detemination of the volume-fraction of martensite in a strained specinen is based on the saturation magnetization of the specinen in a sufficiently strong magnetic field. The saturation magnetization is proportional to the volume-fraction of the magnetically saturated ferromagnetic phase in the specimen. In the presence of a magnetic field $H$ of sufficiently high value the ferromagnetic martensite phase in the specimen acquires a saturation magnetization $M_{\text {sat }}$ with a value corresponding to the highest point on the M vs. $H$ hysteresis curve. Further increases of $H$ do not result in further magnetization of the material beyond $\mathrm{M}_{\text {sat }}$. The value of $M_{\text {sat }}$ is a material constant independent of stresses and strains in

the ferromagnetic phase, ${ }^{3}$ although the value of $H$ necessary to achieve $M_{\text {sat }}$ rises somewhat as the dislocation density of the material increases with plastic deformation. The requirement that a sufficiently high value of $H$ was produced by the field source to achieve saturation magnetization of the martensite phase was checked by observing the $M v S$. $H$ hysteresis curve on an $X-Y$ recorder of a specimen with the martensitic transformation product present. The peak magntitude of H available from the field source (a thick copper coil) was more than sufficient to display that part of the hysteresis where $M$ no longer shows an increase with higher values of $\mathrm{H}$. 
The magnetic measurements were taken with the apparatus in Fig. 4. $D$ and $C$ are coils of finely wound wire, of several thousand tums. The field coil A is designed to carry the current which creates the $H$-field; the H-field varies directly with the current in $A$, so the coil is designed to carry very large currents in its thick windings when a maximum value of $H$ is required. As $H$ varies with time (i.e., by varying the currents in A), the 1 lux $\phi_{i}$ through the loop of coil D varies accordingly; this results in an emf across the $i$-th loop. The total emf across coil D at any instant is

$$
\Delta V_{D}=\sum_{i=1}^{N_{D}} A_{i} \frac{d H}{d t}=N_{D} A_{D} \frac{d H}{d t}
$$

$A_{i}=$ identical area included by each turn

$N_{D}=$ number of turns in coil $D$

Similarly for coil $\mathrm{C}_{2}$

$$
\Delta V_{C}=N_{C} A_{C} \frac{d H}{d t}
$$

As $H(t)$ increases monotonically with time from $H(0)=0($ at $t=0)$ to $H\left(t^{\circ}\right)$, the voltage drop across each coil is the input signal to separate integrators D and C for each coil.

$$
\begin{aligned}
& V_{O D}=K_{D} N_{D} A_{D} \int_{t=0}^{t=t^{\circ}} \frac{d H}{d t} d t=K_{D} N_{D} A_{D} H\left(t^{\circ}\right) \\
& V_{O C}=K_{C} N_{C} A_{C} \int_{t=0}^{t} \frac{d H}{d t} d t=K_{C} N_{C} A_{C} H\left(t^{\circ}\right) .
\end{aligned}
$$

$K_{D}$, and $K_{C}$, are the amplification constants of the separate integrators, and are equalized by a voltage dividex, which in this case reduces the signal from the integrator for coil $C$ to match the output from integrator $D^{\circ}$. 
When specimen with a ferromagnetic phase present is inserted in coil D so that its gage runs down the full length of the coil, the equation for output of integrator $\mathrm{D}^{-}$becomes

$$
\begin{aligned}
& V_{O D^{-}}=K_{D} N_{D} A_{D} \int_{t=0}^{t^{\prime}} \frac{d H}{d t} d t+K_{D} \cdot N_{A} A_{S} V_{\alpha} \int_{t=0}^{t} \frac{d M}{d t} d t \\
& A_{S}=\text { cross-section of gage } \\
& V_{\alpha}=\text { vol.-Eraction of martensite }
\end{aligned}
$$

Carrying out the integration,

$$
V_{O D}=K_{D}{ }^{N} D_{D} A_{D} H\left(t^{D}\right)+K_{D}{ }^{N} N_{D} A_{S} V_{\alpha} M\left(\hat{\tau}^{D}\right)
$$

$M\left(t^{\circ}\right)$ is the magnetization of the ferromagnetic phase, and is expressed as a function of $t$ only because $H$ is a function of $t$; $i . e$, $M=M(H(t))$.

At a sufficiently high value of $H$, the saturation magnetization value $M_{\text {sat }}$ of the ferromagnetic phase is achieved. In the experimental procedure $H$ was increased with time to a level more than sufficient to achieve saturation magnetization, so that the difference between $V_{\text {OD }}$ and $V_{O C}$ was $K_{D} N_{D}{ }_{S}{ }^{M}$ sat, as opposed to zero difference when no ferromagnetic material was present. This difference in the integrated voltages across the two coils was recorded.

$$
\Delta V=V_{O D}-V_{O C}=K_{D} D_{D}^{A} S V_{\alpha}^{M} S a t
$$

Since $N_{D}, K_{D}$ and $M_{S a t}$ are constants, their product is a constant $K^{*}=N_{D} K_{D} M_{\text {sat }}$ so $\Delta V=K^{*}\left(A_{S} V_{\alpha}\right)$. Dividing $V$ by the known cross-section $A_{S}$ of the specimen, $\frac{\Delta V}{\hbar_{S}}=K V_{\alpha}$ is seen to be a number proportional to the volume-fraction of ferromagnetic phase. 
The calibration constant $\mathbb{K}$ was determined by comparing values of $X V_{\alpha}=\Delta V_{\alpha}$ from the magnetic measurements with values of $V_{\alpha}$ detemined for the same specimen by another method, point-counting on the polished and etched gage surface. 


\section{RESULTS}

This section is presented in four parts, each part for the test results of specimens of one of the four tensile orientations studied.

\section{A. [100] Tensile Orientation}

Virtua11y no martensitic transformation occurred in the [100] specimen strained at $-92^{\circ} \mathrm{C}$. Therefore no [100] specimen was tested at $-10^{\circ} \mathrm{C}$. The purpose of testing specimens at $-10^{\circ} \mathrm{C}$ was to compare the strain-hardening behavior of a specimen with almost no martensitic transformation to that of a specimen of identical orientation tested at a lower temperature at which the strain-induced martensitic transformation occurs to a significant extent. Since almost no martensitic transformation occurred at $-92^{\circ} \mathrm{C}$ at this orientation, no such comparison would have been possible with a [100] specimen strained at a higher temperature.

In the [100] orientation the resolved shear stress is equal on eight $\{111\}-<100>$ slip systens. The slip directions are at $45^{\circ}$ from the tensile axis. The expectation that deformation will occur from the outset of plastic strain on a11 four $\{111\}$ planes was confirmed by visual observation of slip lines on the polished $\{100\}$ gage surfaces. Thus at least one $\{111\}-<110>$ sip system was active on each \{111\} plane. 
The yield stress of 14500 psi resolves to a shear stress of 5900 psi on the favored slip systems. Necking occurs at a normal stress of 90,000 psi at $\varepsilon_{\mathrm{p}}=.41$ (plastic strain). The strain-hardening curve (Fig. 5) from the yield point is steep and nearly linear from the yield point to about $20 \%$ plastic strain, and has a modulus of about 250,000 psi. At higher strains the plastic modulus decreases gradually until fracture. In this specimen Stage II strain hardening behavior is displayed immediately upon yielding, ${ }^{4}$ as there is no initial range of strain within which single-slip is the only mode of deformation (Stage 1).

\section{B. [123] Tensile Orientation}

The [123] tensile orientation favors initial slip on only one $\{111\}-<110>$ system, at $17^{\circ}$ from the tensile axis. It was found that slip activity was indeed confined to this system - throughout straining to fracture, for both the $-92^{\circ} \mathrm{C}$ and $-10^{\circ} \mathrm{C}$ specimens. The resolved shear stress sufficient to cause initial yielding on the favored slip system was far exceeded on another $\{111\}-<110>$ system on another $\{111\}$ plane as strain-hardening proceeded, but no slip activity was observed on this other \{111\} plane (this latent hardening phenomenon is observed in many FCC materials). The total suppression of slip activity on this $\{111\}$ plane may be due to the great amount of slip (and $\varepsilon$-hcp phase) which had already occurred throughout the gage on the initial \{111\} plane, by the time the critical resolved shear stress for initial yielding (in the undeformed state) was reached on the second potential slip plane. 
The yield stress was 8500 psi for the $-92^{\circ} \mathrm{C}$ specimen, and 10,500 psi for the $-10^{\circ} \mathrm{C}$ specimen. These resolve to shear stresses of 3900 and 4400 psi respectively on the favored slip system. The $-92^{\circ} \mathrm{C}$ specinen has a slightly decreasing flow stress to about 7\% plastic strain. $\varepsilon_{p}$ increases abruptly halfway between the data points at $\varepsilon_{\mathrm{p}} \sim .07$ and $\varepsilon_{\mathrm{p}} \approx .12$. Between $\varepsilon_{\mathrm{p}} \approx .11$ and until a rapid decrease just before fracture (at 58\% strain, $132,000 \mathrm{psi}$ ), $\mathrm{E}_{\mathrm{p}}$ is relatively constant, decreasing slowly from an average value of 260,000 psi between $\varepsilon_{\mathrm{p}} \sim .12$ and $\varepsilon_{\mathrm{p}} \approx .21$.

The $-10^{\circ} \mathrm{C}$ strain-hardening curve of the [123] orientation is much less steep than that of the $-92^{\circ} \mathrm{C}$ specimen. Between yield and $\varepsilon_{\mathrm{p}} \sim .14$, $E_{\mathrm{p}}$ averages only 25,000 psi. Between $\varepsilon_{\mathrm{p}} \sim .14$ and $\varepsilon_{\mathrm{p}} \sim .55$, in the steeper leg of the $s-$ shape, $\varepsilon_{\mathrm{p}}$ averages $94,000 \mathrm{psi}$. A gradual decrease of $E_{\mathrm{p}}$ occurs in the last $20 \%$ of the curve until necking at $\varepsilon_{\mathrm{p}} \sim 73 \%$, at a stress of 62,000 psi. The volume fraction of martensite at necking was less than $.25 \%$ in the $-10^{\circ} \mathrm{C}$ specimen, as contrasted with a volume fraction of $24^{\circ}$ in the $-92^{\circ} \mathrm{C}$ specimen at necking.

The strain-hardening curves of the $-92^{\circ} \mathrm{C}$ and $-10^{\circ} \mathrm{C}$ specimens are shown in Fig. 6, while the difference $\Delta \circ$ in flow stress between the $-92^{\circ} \mathrm{C}$ and $-10^{\circ} \mathrm{C}$ specimens is plotted in Fig. 7. The volume-fraction of martensite is plotted against strain in Fig. 8 for all tensile orientations tested which displayed a significant volume fraction of martensite. In Fig. 9, $\Delta \sigma$ is plotted against the volume-fraction of martensite found at the corresponding level of strain at $-92^{\circ} \mathrm{C}$ for the [123] orientation. 
As noted, the earliest part of the strain-hardening cunves of both the $-92^{\circ} \mathrm{C}$ and $-10^{\circ} \mathrm{C}$ specimens is nearly level. In this early stage of straining the $-92^{\circ} \mathrm{C}$ specimen the first martensitic transformation and accomodation slip of austenite initiated in many distinct bands extending across the gage surface along the traces of the $\{111\}$ slip plane. Some slip was also occurring in the austenite outside of these bands, especially in the austenite immediately adjacent to the bands. The widening and proliferation of these bands with strain at a constant flow stress can be likened to deformation of a crystal by propagation of a Luders band along its length. This process of martensite band extension and formation is illustrated in Figs. 10a,b,c,d. Here the specimen was strained first a few percent at $-92^{\circ} \mathrm{C}$ with the resulting surface appearance in Fig. 10a. The accomodation shear in the austenite in the confines of the martensite band is marked by the light contrast due to the surface tilt of the sheared austenite. Figure $10 \mathrm{~b}$ shows the appearance of a similar surface after electropolishing and etching: the martensite needles which were formerly marked by the tilt at the intersection of needle with gage surface are now seen from etching, but in the absence of the polished-away slip lines or tilt in the austenite. The needles, known to have a rectangular cross-section, intersect the \{111\} gage surface at glancing angles, as the long axes of the needles are close to the <110> directions on the slip plane. Those needles which have their long axes approximately parallel to the single active <110> slip direction on the slip plane are seen in light relief in nearly 
longitudinal section, since this <110> slip direction is parallel to the $\{111\}$ gage surface examined. Figures $10 \mathrm{c}$ and $10 \mathrm{~d}$ show the surface after another increment of strain. No evidence of slip or further transformation is seen in the previously formed bands of martensite.

A phenomenon noted at all tensile orientations at which significant amounts of martensite formed is the evidence of slip in the austenite immediately adjacent to the bands of martensitic transformation and accomodatively sheared and tilted austenite. In Fig.10a, which is obliquely illuminated, the tilt of the austenite in the $\{111\}$ transformation band is plainly seen by the light contrast. Plainly the accomodation shear in the austenite has a component normal to the plane of the micrograph. To one side of each shear and transformation band a region of concentrated slip occurs in the austenite. It can only be a matter of speculation as to whether this slip occurred before, during, or after the formation of the bands of martensite and accomodative austenite shear within the bands.

\section{C. [112] Tensile Orientation}

The [112] specimens are oriented to favor slip on two $\{111\}-<110>$ sIip systems, each on a different \{111\} plane. The two predicted $\langle 110\rangle$ slip directions are $30^{\circ}$ from the tensile axis. The active slip systems in the strained crystals observed were those predicted.

The yield stress was 10,500 psi for both the specimen tested at $-92^{\circ} \mathrm{C}$ and the specimen tested at $-10^{\circ} \mathrm{C}$. This resolved to a shear stress of 4300 psi on the favored slip systems. The specimen tested at $-92^{\circ} \mathrm{C}$ necked at $100,000 \mathrm{psi}, \varepsilon_{\mathrm{p}}=.51$. The $-92^{\circ} \mathrm{C}$ specimen has a 
very mild suggestion of an S-shaped strain-hardening curve. Between $\varepsilon_{\mathrm{p}}=0$ and $\varepsilon_{\mathrm{p}}=.08$, plastic modulus $\mathrm{E}_{\mathrm{p}}$ is about 175,000 psi. Between $\varepsilon_{p}=.12$ and $\varepsilon_{p}=.24, E_{p}$ averages to 265,000 psi. Between $\varepsilon_{p}=.28$ and $\varepsilon_{p}=.51$, the steadily declining $E_{p}$ averages to 115,000 psi. Perhaps significantly, the plot of volume fraction of martensite vs. $\varepsilon_{\mathrm{p}}$ for the [112] specimen also has the faint suggestion on an S-shape for [112] orientation. The martensitic transformation proceeded ultimately to a volume fraction of $18 \%$ before necking. The $-10^{\circ} \mathrm{C}[112]$ specimen has a much less steep strain-hardening curve than the $-92^{\circ} \mathrm{C}$ specimen. Up to $\varepsilon_{\mathrm{p}} \sim 12, \mathrm{E}_{\mathrm{p}}$ is constant at $125,000 \mathrm{psi}$. From $\varepsilon_{\mathrm{p}} \sim .12$ to necking at $\varepsilon_{\mathrm{p}}=.54, E_{\mathrm{p}}$ declines gradually to a value of 50,000 psi for the 1 ast $16 \%$ of strain. Necking occurs at 60,000 psi. The volume fraction of martensite was less than .25\% before necking. The strain-hardening curves of the [112] specimens are shown in Fig. 11. The difference $\Delta 0$ in flow stress between the $-92^{\circ} \mathrm{C}$ and $-10^{\circ} \mathrm{C}$ specimens for $\varepsilon_{\mathrm{p}}<5 \%$ is plotted in Fig. 12. In Fig. $13 \Delta 0$ is plotted against the volume-fraction of martensite in the $-92^{\circ} \mathrm{C}$ specimen at the corresponding level of strain.

In both specimens slip activity on the two $\{111\}$ slip planes was fairly equally distributed between them. Because the active slip directions were at $30^{\circ}$ angles to the tensile axis, the geometry of the situation assured that from the onset of strain the active slip bands (e.g., bands of maxtensite) extending across the gage at $-92^{\circ} \mathrm{C}$ on both $\{111\}$ planes intersected each other along all parts of the gage. like the [100] specinen, these specimens proceeded with Stage II 
hardening immediately, with no single-slip defomation early in the straining process. The martensite needles in the $92^{\circ} \mathrm{C}$ specimen were fairly evenly distributed between the two active $\{111\}$ siip planes, as observed from the occurrence of transformation bands on the two planes.

A specimen of [112] orientation was strained to only $\varepsilon_{\mathrm{p}} \sim .20$ at $-92^{\circ} \mathrm{C}$, in addition to the specimen strained to fracture at this temperature. In this specinen, apparently slightly misoriented, nost of the martensite occurred on one slip plane (Fig. 14a). The distribution of shear stress and shear strain occurring on each of the two $\{111\}$ planes is not obvious, however. The contribution to strain of accomodation shear and transformation shear depends on the needle variants which are forming on the plane. Probably most of the accomodation shear in the austenite contribures to specimen elongation, as in Fig. 14a. The observed concentration of slip on the same plane adjacent to a transformation band also contributes to specimen elongation, though it is not lonown in wich [110] directions this siip is occurring since it may be partially generated by the transfomation in the adjacent bands rather than simply by the resolved shear stress on the slip plane. The slip lines of the [111\} plane with less martensite were relatively widely and regularly spaced, as if for a primary slip system. In some localities of the specimen virtually all slip not associated with the transformation bands was associated with the non-transfoming plane (Fig. 14b). While the [112] specinen tested at $-10^{\circ} \mathrm{C}$ had a rairly even distribution of slip. in those few 
localities where transfomation bands appeared all the slip activity was on the intersecting $\{111\}$ plane (Fig. 14C). Figure 14c does not represent a typical sample of the surface of the $-10^{\circ} \mathrm{C}[112]$ specimen, as it shows a much greater local occurrence of tiny transformation bands than were actually present along most of the gage.

For both [112] specimens tested at $-92^{\circ} \mathrm{C}$, in the active $\{111\}$ planes the martensitic bands cover progressively a larger fraction of the specimen as straining proceeds, as in the single-slip [123] orientation "Luders band" analogue. In other words, the increases in vol-: martensite with strain occurs by fresh nucleation of martensite outside the previously observed transformation bands, rather than by concentration of further transfomation in the martensite bands already present. At higher strains, further increase in vol-\% martensite occurs by the increase of transfomation product within bands already present that now occupy virtually the entire crystal volume with martensite and accomodation-slipped austenite in its vicinity. In highly strained crystals, the bands of martensite cannot be distinguished as such because the distribution of martensite needles is uniform throughout the crystal.

This second [112] specimen strained only to $20 \%$ was utilized for a measurement of the effect of temperature on yield stress. After straining to $14 \%$ at $-92^{\circ} \mathrm{C}$, the specimen had strain-hardened to a flow stress of $35,000 \mathrm{psi}$ and a $4 \%$ volume fraction of martensite. The load was removed and the specimen bath removed. After the specimen was at room temperature, the straining process was resuned. 
The initial flow stress at room temperature was raised by about $10 \%$ to $38,000 \mathrm{psi}$, and in the course of straining from $14 \%$ to $17 \%$ elongation the value of $E_{\mathrm{p}}$ was unchanged (within the Iimits of accurate measurement over a small increment of strain) from the value observed over the previous increment of plastic strain to $14 \%$ at $-92^{\circ} \mathrm{C}$. The load was then again removed and the specimen was reimmersed in the $-92^{\circ} \mathrm{C}$ bath, still in its grips. Arother $3 \%$ increment of plastic strain, to $20 \%$, was applied at $-92^{\circ} \mathrm{C}$. The initial flow stress dropped by $16 \%$ from the flow stress observed before the load was removed at $17 \%$ strain, from 46,000 psi to 38,500 psi. $E_{p}$ in the interval to $17 \%$ strain to $20 \%$ strain at $-92^{\circ} \mathrm{C}$ remained at the same value as the two previous increments, and at $20 \%$ strain the flow stress had again risen to 47,000 psi.

\section{D. [110] Tensile Orientation}

The [110] tensile orientation favors initial slip on four $\{111\}-<110>$ systems, two on each of two $\{111\}$ planes. The favored <10> slip directions are all at $60^{\circ}$ from the tensile axis. The specimen tested at $-92^{\circ} \mathrm{C}$ exhibited slip on only one of the two expected slip planes, though the tensile axis of the specimen was within $.5^{\circ}$ of a [110] direction. The $-10^{\circ} \mathrm{C}$ specimens also exhibited slip on only one of the \{111\} planes initially favored. However; at the very high strains encountered in the $-10^{\circ} \mathrm{C}$ specimens, sip also occurred on another \{111] plane which initially had zero resolved shear stress. The large effect of tensile axis rotation involved in straining these specimens beyond 100\% (and undoubtedly an imbalance of 
of slip activity between the two favored $\{110\}$ slip directions on the predominating slip plane) would justify the eventual occurrence of some slip on a \{111\} plane which was parallel to the tensile axis at the outset of straining; however, it is unexpected that the latent hardening phenomenon would prohibit slip on the $\{111\}$ plane with a nominally identical resolved shear stress as the predominating slip plane while allowing slip (presumably initiated at very high strains) on a plane with an initial resolved shear stress of zero before tensile axis rotation upon straining.

The yield stress was 10,500 psi for the $-92^{\circ} \mathrm{C}$ specimen, resolving to a shear stress of 4300 psi on the favored slip systems. The $-92^{\circ} \mathrm{C}$ specimen has a nearly level flow stress to about 7\% strain (actually, a small reduction occurs between yield and $\sim 5 \%$ ) and an abrupt uptum which occurs about halfway between the data points at $5 \%$ and $11 \%$ strain. As for the single-slip [123] specimen, $E_{p}$ increases rapidly from this "comering" point to a maximum of about 540,000 psi at $17 \%$ strain. $E_{p}$ subsequently declines gradually to about 150,000 psi at $27 \%$ strain and remains at this value up to necking at $86 \%$ strain. at 122,000 psi.

The $-10^{\circ} \mathrm{C}$ specimens have nearly linear strain-hardening curves from the outset. The specimen strained by increments initially yielded at 11,800 psi and necked at 112\% strain, at 107,000 psi. The continuously strained specimen yielded initially at 10,500 psi and necked at $140 \%$ strain, 110,000 psi. The average values of $E_{p}$ for the incrementally strained and continuously strained specimens 
respectively were 78,000 and 70,000 psi respectively. The strainhardening curves for the [110] orientation are plotted in Fig. 15. The difference $\Delta o$ in flow stress between the $-92^{\circ} \mathrm{C}$ specimen and the $-10^{\circ} \mathrm{C}$ specimen that was continuously strained is plotted in Fig. 16. In Fig. $17 \Delta \sigma$ is plotted against volume-fraction of martensite. As in the case of the [123] tensile orientation, the $-92^{\circ} \mathrm{C}[110]$ specimen also exhibited a "Luders band" effect as transformation bands on the single active slip and transformation plane propagated along the length of the gage in the earliest stage of the straining process. 


\section{DISCUSSION}

\section{A. Ductility}

The specimens tested at $-10^{\circ} \mathrm{C}$ necked at a greater strain than the specimens of identical orientation strained at $-92^{\circ} \mathrm{C}$. The much larger extent of transformation to martensite at $-92^{\circ} \mathrm{C}$ vs. $-10^{\circ} \mathrm{C}$ in the $[123]$, [112], and [110] orientations, and the effects of this higner rate of transformation on the stresses achieved at a given elongation, may be a major cause of this ductility reduction beyond the effect of the temperature difference on the ductility of austenite). The effect is not large for the [123] and [112] orientations, but is considerable for the [110] orientation. The observed differences in ductility between the different orientations at one temperature overwhelm differences occurring between specimens of one orientation strained at different temperatures. For specimens of differing orientation strained at the same temperature $\left(-92^{\circ}\right.$ or $\left.-10^{\circ}\right)$, ductility increases as the number of active slip systems active at each respective orientation decreases. Thus at $-92^{\circ} \mathrm{C}$ the [110] specimen, with four active slip planes and almost no maxtensite, has a final elongation on $1 y$ 11\%. The [112] specimen, with two active slip planes, elongates to 51\%. The [123] and [110] specimens have only one active slip plane, and they elongate to $61 \%$ and $81 \%$ respectively. A similar order is present among the $-10^{\circ} \mathrm{C}$ specimens, where the [112] specimen has the least elongation (no [100] specimen was tested at $-10^{\circ} \mathrm{C}$ ) and the $[110]$ specimens elongate an average of $130 \%$. There may be some significance to the fact that those specimens 
with a greater number of active slip systems are also the ones with the least tendency to martensitic transformation. In polycrystal TRIP steels the strain-induced martensite is considered to enhance ductility. 5

\section{B. Yield Points}

The yield points of all specimens are tabulated in Table I. These values of resolved shear stress at yielding are generally in close agreement with Stone's data, also tabulated. The fact that the highest CRSS is observed in the specimen with the least tendency to martensitic transformation with straining (i.e., the "least metastable" specinen) is consistent with the relationship between metastability and initial yield stress observed by Breedis and Robertson. 6 The latter have demonstrated that metastability of austenite will have the effect of reversing the usual trend towards an increase in yield stress with decreasing temperature, at least in the lower part of the metastable temperature range. While the yield points for the [110] and [112] orientations do not in all cases have a reduced yield stress at reduced temperature $\left(-92^{\circ} \mathrm{C} v \mathrm{vs}-10^{\circ} \mathrm{C}\right)$, the general trend of the yield data agrees we11 with the results of Stone and of Breedis and Robertson.

The results from the [112] specimen strained to only $\varepsilon_{\mathrm{p}}=.20$ are unfortunately derived from a very narrow data base, and hence may lack experimental significance. They do touch upon an aspect of great importance to the usefulness of cold-working metastable austenite, namely the question of whether the high flow stress levels attained 
with straining at $-92^{\circ} \mathrm{C}$ are indeed retained, or even enhanced, when the cold-worked materjal is tested at room temperature. The [112] experiment suggests this is the case, and also that the high strainhardening modulus observed at $-92^{\circ} \mathrm{C}$ may be retained at room temperature over a short range of further strain. One would expect that more extensive straining of the [112] specimen would eventually lead to a drop of this modulus because the vol-: martensite is no longer increasing with strain, as it is at $-92^{\circ} \mathrm{C}$. The large drop in yield point when the [112] specimen was strained from $17 \%$ to $20 \%$ at $-92^{\circ} \mathrm{C}$ arter being strained at room temperature from $14 \%$ to $17 \%$ may be a result of the reduction of yield stress of austenite in the lower part of the metastable range, as already noted.

\section{Strain Hardening}

The virtual absence of the strain-induced martensite transformation in the specinens tested at $-10^{\circ} \mathrm{C}$, as contrasted to the large extent of this transformation observed at $-92^{\circ} \mathrm{C}$, must account for a large part of the much higher strain-hardening rates observed at each orientation at the lower temperature. The effect of the martensite phase on the strain-hardening rate may also account for the sharp uptum of the strain-hardening curves of the [110] and [123] specimens in the vicinity of $5 \%$ to $10 \%$ strain. The early mode of single-slip deformation by extension of initial bands of stip and transformation product may account for the nearly constant flow stress at the first stages of strain. The point at which the strain-hardening curves of the $-92^{\circ} \mathrm{C}$ 
specimens tum sharply upwards (in marked contrast to specimens of like orientation at $-10^{\circ} \mathrm{C}$ ) could be the point at wich a major part of further deformation on transformation must proceed in the context of slip within the previously formed slip and shear bands containing the martensite which formed in the initial process of Luders-type slip band/txansformation band extension.

The $\Delta \sigma$ vs, vol-\% martensite curves of the [123] and [110] singleslip specimens are quite similar in shape and have a close correspondence of slopes at equal volume-fractions of martensite. The $\Delta \sigma$ vs. vol- curves rise rapidy to maximum slope values between $6 \%$ and $9 \%$ vol- $\frac{\sigma}{6}$ after the initial constant-stress stage of slip/transformation band propagation. These slopes are significantly reduced and nearly constant at vol.-fractions above 12\%-15\%. The $\Delta \sigma \mathrm{vs}$. vol.- $\frac{\%}{6}$ martensite curve for the [112] specimens shows a positive and increasing slope from the outset of plastic strains, reflecting the absence of an initial constant-stress stage of deformation in wich the strain occurs solely by initial slip/transformation band propagation rather than by deformation within the regions where martensite has been formed. The [112] $\Delta \sigma$ vs. vol. -\% curve falls rapidly after about 8\% vol.-fraction, and at vol. $-\frac{0}{0}$ above $10 \%$ has less than half the slope of the $\dot{\Delta} \mathrm{J}$ v. vol.- $\%$ curves of the single-slip specimens at similar vol.-fractions of martensite. Comparison of the $\Delta \sigma$ vs. vol. $-\%$ curves between the single-slip and [112] specimens may indicate that the martensite contributes proportionately much less to the strain-hardening rate of 
the [112] specimen at vol. - above $10 \%$ than to the strain-hardening rate of the [123] and [110] specimens.

\section{Effect of Tensile Orientation on Volume-Fraction of lartensite}

Patel and Cohen ${ }^{7}$ have considered the interaction of an applied. stress with the displacive shear and dilatation normal to the shear plane during the martensitic transformation. Goodchild and Roberts 8 have used this analysis to predict the effect of the stress axis on the distribution of martensite anong the 24 possible variants. The 24 variants are distributed so that six possible variants are associated with each $\{111\}$ slip plane. The shear system for the martensitic transformation studied here is shown to be $\{112\}-\langle 110\rangle$ in previous studies. The three $\{112\}$ shear planes perpendicular to each $\{111\}$ plane intersect that plane in a $<110\rangle$ 1ine, and the transformation shear may occur in either direction along this $\langle 110\rangle$ line of intersection. Hence the martensite needles are found in twin variants along the direction of the shear along that 1ine. Such twins are seen in Fig. 14, and the light contrast results from the opposite shear directions of the two halves of the twins. Each of the 24 variants is identified by its unique transformation shear. Stone has found the shear to have a magnitude of $\gamma_{0}=.20$, with a dilatation of $\varepsilon_{0}=.04$ normal to the shear plane.

Using the formulation of Coodchild and Roberts adapted from the patel and Cohen analysis, 


\section{0}

$$
\begin{aligned}
& -31- \\
U & =\tau \gamma_{0}+\sigma_{\mathrm{n}} \varepsilon_{0} \\
\text { where } U & =\text { work done } \\
\tau & =\text { resolved shear stress on the habit plane } \\
\sigma_{\mathrm{n}} & =\text { resolved stress normal to the habit plane }
\end{aligned}
$$

The magnitude of $U / \sigma$ for any variant is a relative indication of how effective and applied stress will be in assisting the transformation shear and dilatation. In Table II values of $U / \sigma, \tau / \sigma$, and $\sigma_{n} / \sigma$ are shown for all tensile orientations studied here, but only for the variants which are associated with the planes upon which slip and transformation to martensite were observed at each orientation. Stone has shown that even those variants with relatively high values of $U / \sigma$ will not occur uniess they are associated with a $\{111\}$ plane upon which slip is occurring because of a sufficient resolved shear stress on that plane. The distribution of variants on an active slip plane has been found to correlate well with the values of $U / \sigma$ among those variants, however. For the [100] and [112] tensile orientations, only the variants on one of the several active slip planes are tabulated in Table II, since the other active slip planes have an orientation relative to the tensile axis that is symetrical to that of the $\{111\}$ plane considered. The values of $U / \sigma$ for the variants on each plane are summed, to give a measure of the relative tendency for the tensile stress to assist the transformation shear and dilatation on the active slip planes at each tensile orientation. Comparison of these surmation values with a plot of vol. $-\%$ martensite vs. tensile stress for the $-92^{\circ} \mathrm{C}$ specimens (Fig. 18) reveals that, apart from the [110] specimen, 
the orientations tested show a sequence of decreasing tendency to martensitic transformation (e.g., [123], [112], [100]) that is identical to the sequence predicted by the U/o criterion. However, the vol. $-\%$ martensite observed at a given stress differs much more greatly between these orientations than the values of U/o do. Another way of sorting out these curves is by the number of active slip planes in operation at each tensile orientation. In this respect there is a sequence of decreasing tendency to martensitic transformation identical to the sequence of increasing numbers of active slip planes. In accordance with this trend, it is seen that the tendency to martensitic transformation relative to nomal stress is nearly identical for the [110] and [123] single-slip specimens; this is evident from the close correspondence of the vol.- maxtensite vs. tensile stress curves for these two orientations in Fig. 19. These results, except for [110], correspond well with those reported by Stone, who measured vol.-"\% matensite at 5\% strain for all orientations studied here. Stone suggests that the partitioning of the austenite by sheets of $\varepsilon$-hep on active silp planes would restrict the size of martensite bursts in a multiple-slip specimen such as [112], and hence account for the fact that the [112] orientation displays less martensite relative to the [123] orientation than its only slightly lover U/o would lead one to expect. While the vol. - data from the [110] specimen does not conform to the expectation from the $U / \sigma$ criterion that this orientation should show the least martensite at a given level of stress, it tends to support the idea that the number of active slip systems is the 
main deteminant of tendency to martensitic transformation at a given stress level.

The curves of vol. $-\%$ martensite vs. $\varepsilon_{p}$ for the $-92^{\circ} \mathrm{C}$ specimens do not conform to an equation of the form $(v o l .-\%)=A e^{1 / 2}(e=$ true strain). In fact, they would exhibit either linearity (for [110] orientation) or a sma11 upward parabolic shape ([123] and [112] orientations) if plotted against true strain e. However, if the tendency towards suppression of the martensitic transformation by an increase in the number of active slip is correlated to an increase in the average number of slip planes in operation in the grains of a TRIP steel as strain is increased, a curve of the form (vol.-\% martensite) $=\mathrm{A} \mathrm{e}^{1 / 2}$, could result. Such a relationship has been reported for a polygranular TRIP steel by Gerberich. ${ }^{9}$

Nangonon and Thomas ${ }^{10}$ have shown that yield strength of a 304 stainless steel varies Iinearly with the amount of martensite previously formed by thermal and thermal/mechanical treatment. The curves of vol.- martensite vs. $\varepsilon_{\mathrm{p}}$ tend to justify this observation. Presumably a grain of polycrystalline material will not have an initial range of strain during which a "Luders band" of initial slip and transformation will propagate across the grain. So the section of the single-crystal, single-slip strain-hardening curves relevant to a polycrystalline analogy lies beyond this initial stage. As seen in Fig. 8 the relationship between vol. $-\frac{3}{3}$ martensite and $\varepsilon_{\mathrm{p}}$ is nearly linear for the single-slip specimens. The tendency for the slope to increase at higher stresses could possibly be balanced by a tendency 
for a greater average number of slip systems to be active in the grains of specimens subjected to more severe work-hardening processes, thus leading to a lower vol. $\%$ of martensite corresponding to a given level of yield stress. 


\section{$-35-$}

\section{CONCLUSIONS}

The effect of the martensitic transformation product in increasing the strain-hardening modulus is denonstrated by comparison of the strain-hardening curves obtained by taking specimens at both $-92^{\circ} \mathrm{C}$ and $-10^{\circ} \mathrm{C}$ for different orientations. The superposition of strain-hardening effects due to the martensite upon the normal straindependent and orientation-dependent strain-hardening behavior is evident. When the effect of the tensile orientation and its intrinsic effect on the strain-hardening rate of the austensite and the rate of martensitic transformation is partially discounted by making a plot of $\Delta \sigma$ vS. vol. $-\frac{8}{6}$ martensite, a similarity is evident among these curves for three different orientations.

A yielding phenomenon associated with the initial formation and propagation of bands of slip and transformation product occurs in the single-slip specimens, and this too must be discounted when examining and isolating the effect of the martensitic transformation as it interacts with more usual single-phase strain-hardening behavior at different tensile orientations.

The effect of tensile orientation on the rate of transformation to strain-induced martensite as tensile deformation proceeds is determined by the number of active slip planes in operation in a specimen of a particular orientation. Single-slip specimens will have the highest transformation rates. A specimen with the maximum number of active slip planes (four) will show the least amount of straininduced transformation. 


\section{ACROWLEDGENTS}

The author wishes to express his gratitude to Professor Gareth Thomas for his guidance and encouragement throughout the course of this study. Nany helpful discussions with Dr. David R. Clarke are gratefully acknowledged.

This research was performed under the auspices of the U.S. Energy Research \& Development Administration through the Holecular Materials Research Division at Lawrence Berkeley Laboratory. 
Table I. Yield points of Tensile Specimen.

\begin{tabular}{|c|c|c|c|c|}
\hline & \multicolumn{2}{|c|}{$\begin{array}{l}\text { This Study } \\
\text { CRSS in psi. }\end{array}$} & \multicolumn{2}{|c|}{$\begin{array}{l}\text { Stone's Data } \\
\text { CnSS in psi. }\end{array}$} \\
\hline [112] & $\begin{array}{l}-92^{\circ} \mathrm{C} \\
-10^{\circ} \mathrm{C}\end{array}$ & $\begin{array}{l}4300 \\
4300\end{array}$ & $\begin{array}{r}-92^{\circ} \mathrm{C} \\
0^{\circ} \mathrm{C}\end{array}$ & $\begin{array}{l}4900 \\
8400\end{array}$ \\
\hline [123] & $\begin{array}{l}-92^{\circ} \mathrm{C} \\
-10^{\circ} \mathrm{C}\end{array}$ & $\begin{array}{l}3900 \\
4900\end{array}$ & $\begin{array}{r}-88^{\circ} \mathrm{C} \\
0^{\circ} \mathrm{C}\end{array}$ & $\begin{array}{l}5800 \\
6800\end{array}$ \\
\hline$[110]$ & $\begin{array}{l}-92^{\circ} \mathrm{C} \\
-10^{\circ} \mathrm{C}\end{array}$ & $\begin{array}{l}4300 \\
4300,4800\end{array}$ & $-88^{\circ} \mathrm{C}$ & 5800 \\
\hline$[100]$ & $-92^{\circ} \mathrm{C}$ & 5900 & $-88^{\circ} \mathrm{C}$ & 8700 \\
\hline
\end{tabular}


Table II. Values of $\tau / \sigma, \sigma_{n} / \sigma$, and $u / \sigma$ for martensite variants, computed for the four tensile axes.

[001]

\begin{tabular}{|c|c|c|c|c|c|}
\hline $\begin{array}{l}\text { slip plane } \\
\text { (III) }\end{array}$ & $\begin{array}{c}\text { shear plane } \\
(211)\end{array}$ & $\begin{array}{c}\text { shear direction } \\
{[0 \overline{1} 1]}\end{array}$ & $\begin{array}{l}\tau / \sigma \\
.288\end{array}$ & $\begin{array}{l}\sigma_{n} / \sigma \\
.167\end{array}$ & $\begin{array}{l}0 / \sigma \\
.064\end{array}$ \\
\hline (111) & $(211)$ & {$[011]$} & -.288 & .167 & -.051 \\
\hline (I11) & (112) & {$[110]$} & 0 & .667 & .027 \\
\hline (I11) & (1I2) & [110] & 0 & .667 & .027 \\
\hline (111) & (121) & {$[101]$} & .288 & .167 & .064 \\
\hline (T11) & (121) & [101] & -.288 & .167 & -.051 \\
\hline
\end{tabular}

[011]

(I11)

(111)

(111)

(111)

(111)

(11)

(211)

[011]

(211)

[01]]

(112)

[110]

(112)

[10]

(121)

[101]

(121)

[10]]

$$
\begin{array}{ccc}
0 & .333 & .013 \\
0 & .333 & .013 \\
.144 & .0832 & . .032 \\
-.144 & .0832 & -.025 \\
-.144 & .0832 & . .025 \\
.144 & .0832 & .032 \\
\sum_{i} U_{i} / 0= & .0406
\end{array}
$$

\begin{tabular}{|c|c|c|c|c|c|}
\hline (111) & (211) & [011] & -.103 & .0118 & -.020 \\
\hline (111) & $(2 \pi 1)$ & $[0] 1]$ & .103 & .0118 & .022 \\
\hline (111) & $(112)$ & [110] & .432 & .583 & .110 \\
\hline (111) & $(112)$ & {$[110]$} & -.432 & .583 & -.063 \\
\hline (111) & (121) & {$[10 \overline{\mathrm{I}}]$} & -.659 & .761 &. .101 \\
\hline (III) & (I21) & [101] & .659 & .761 & .162 \\
\hline
\end{tabular}

[123] 


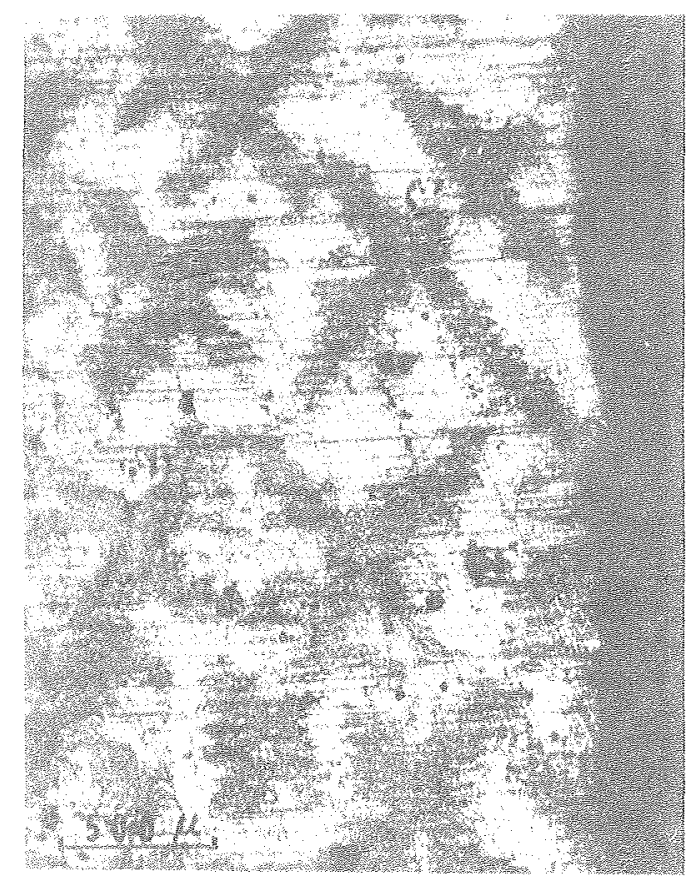

$\mathrm{Fig}, 1$

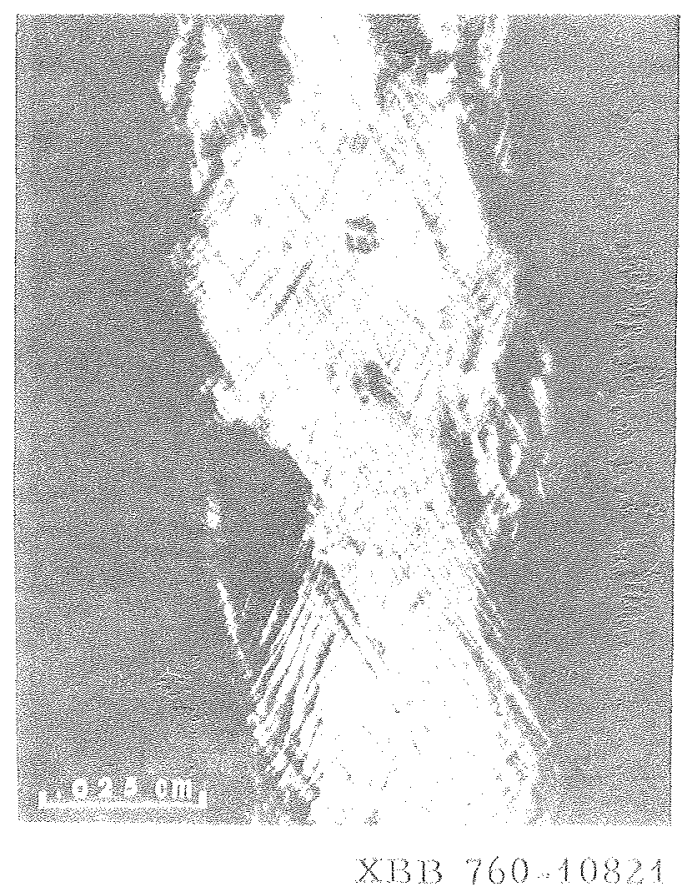

fig. 


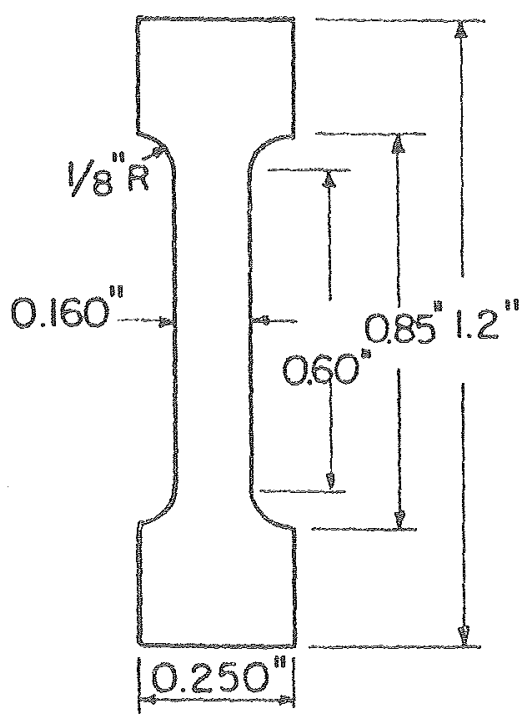

Specimen $0.045^{\prime \prime h i c k}$

Fig. 3.

Field Coil A

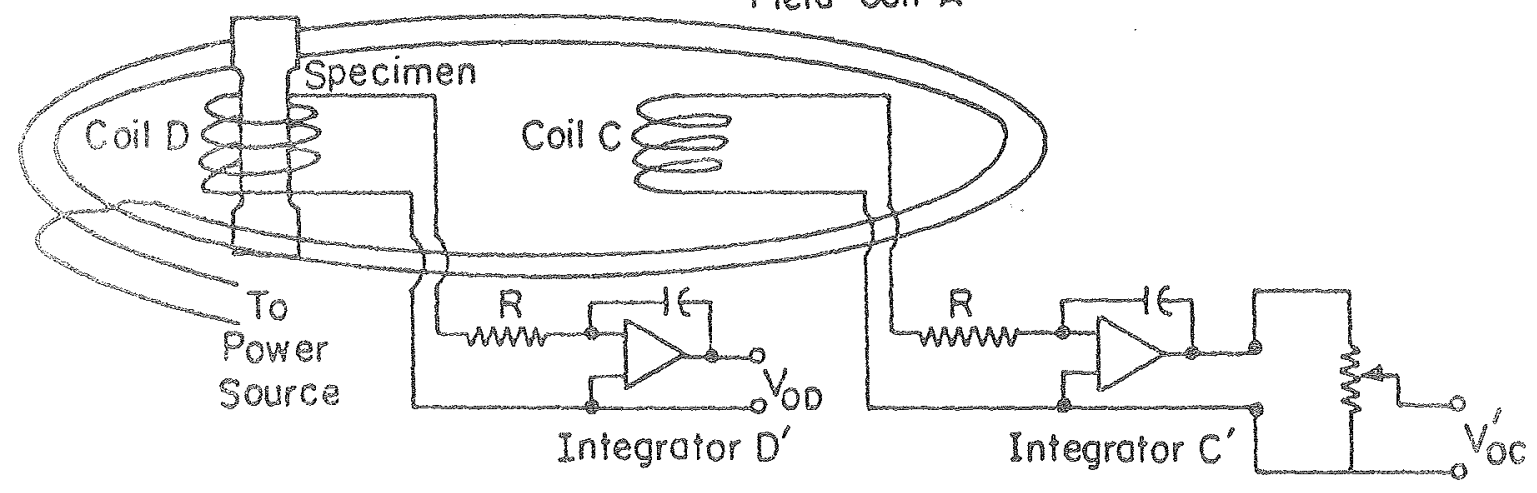

X8L761107833

Fig. 4 


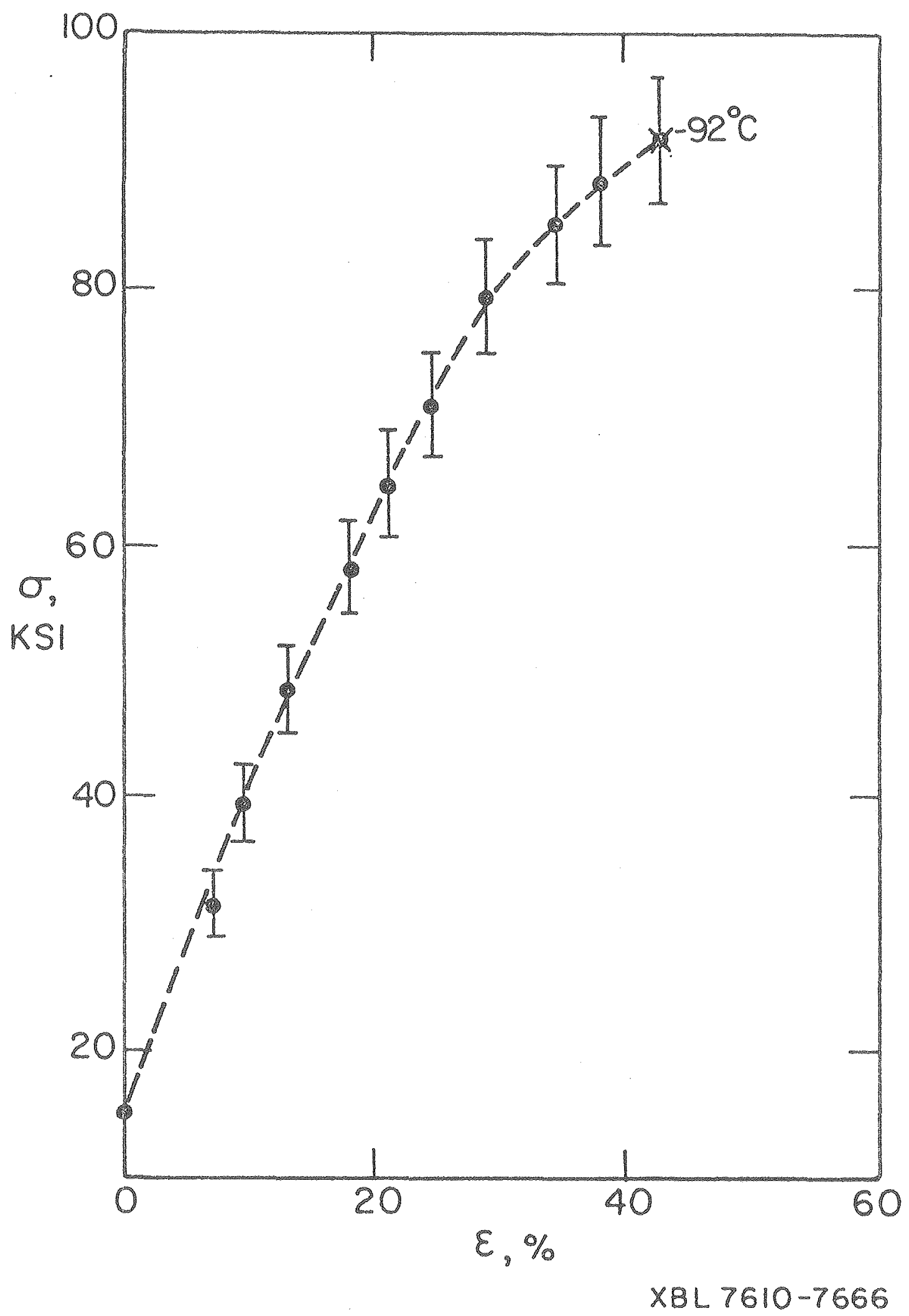

Fig. 5. 


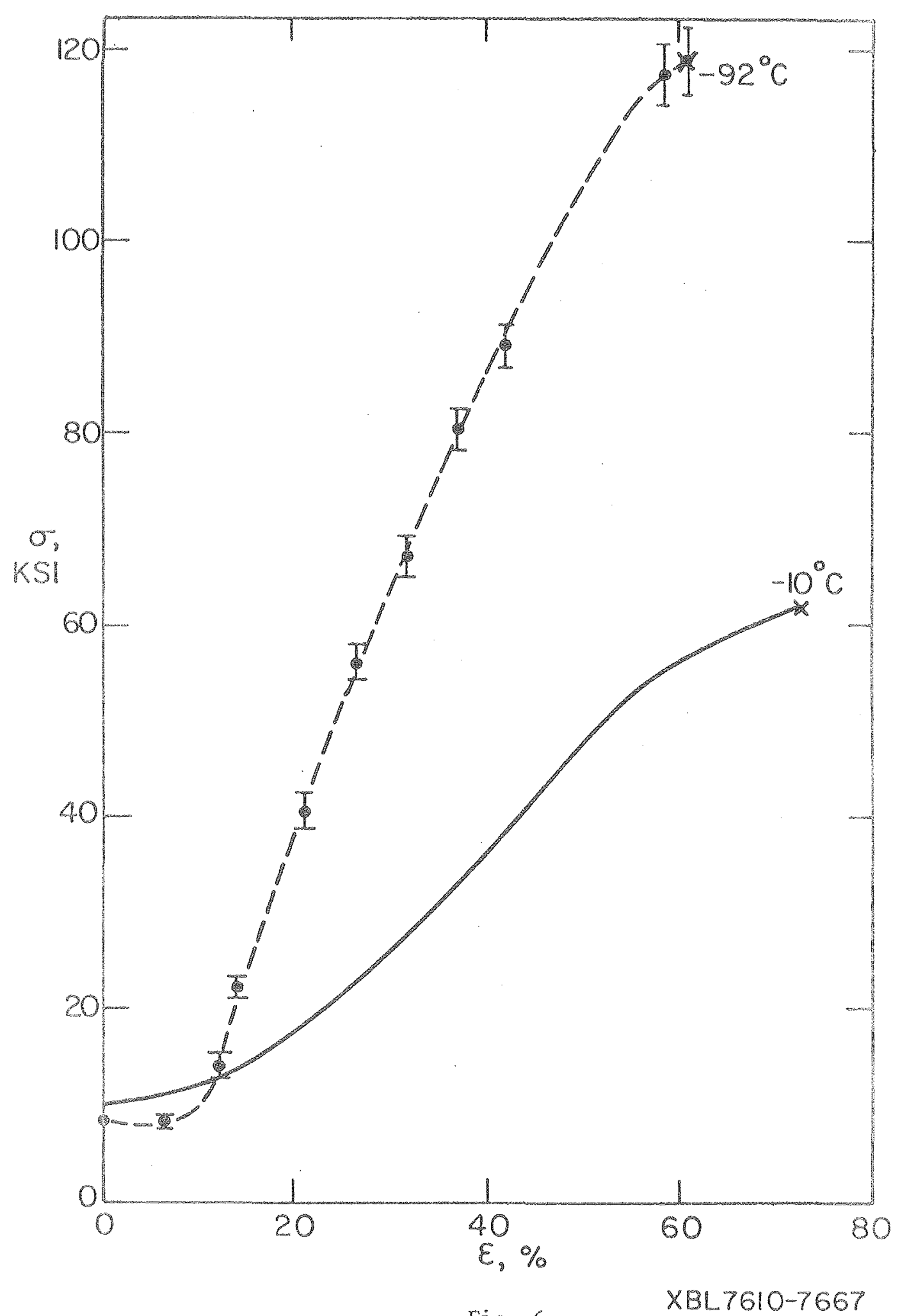

Fig. 6 . 


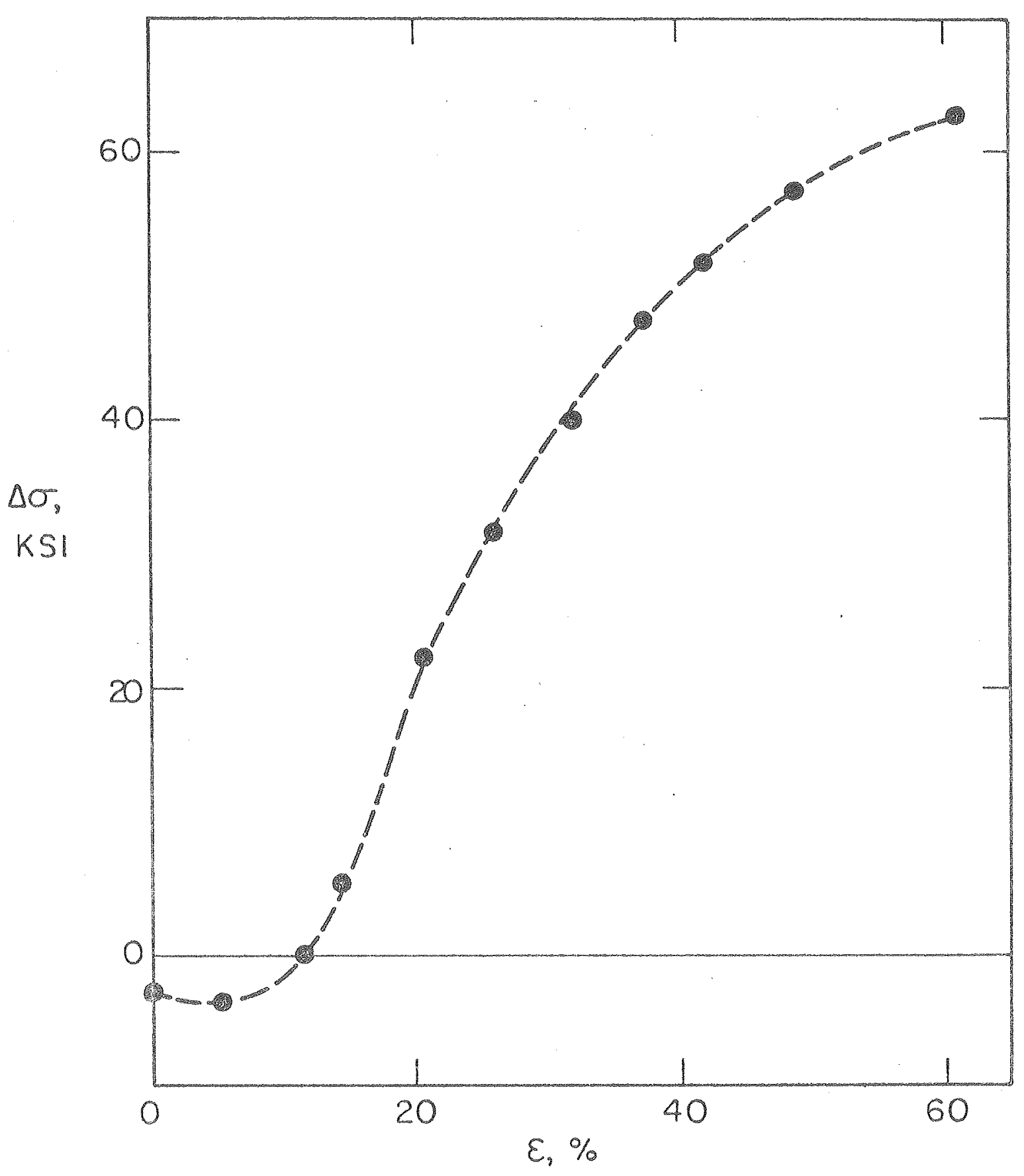

XBL7610-7664

Fig. 7. 


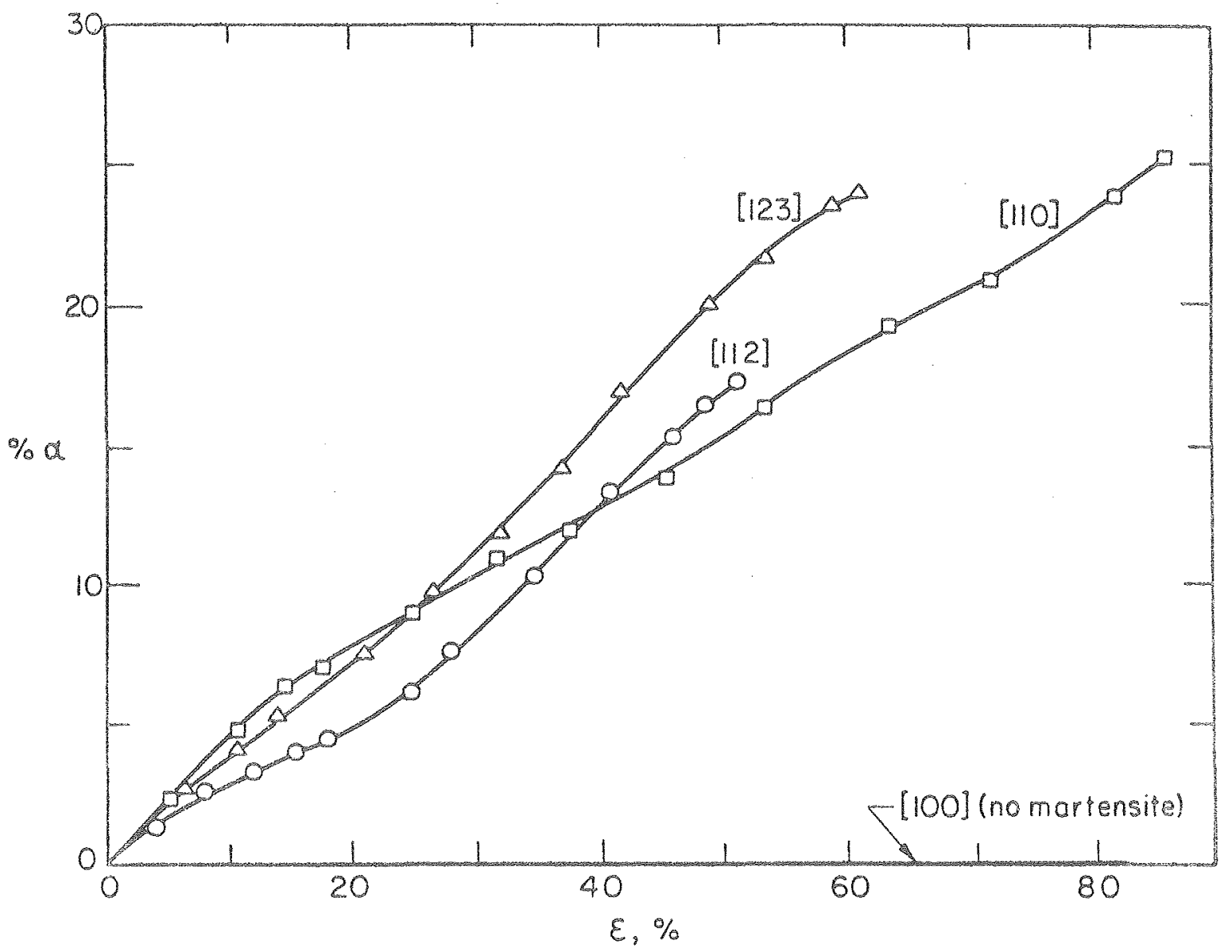

Fig。 o. 
$-46-$

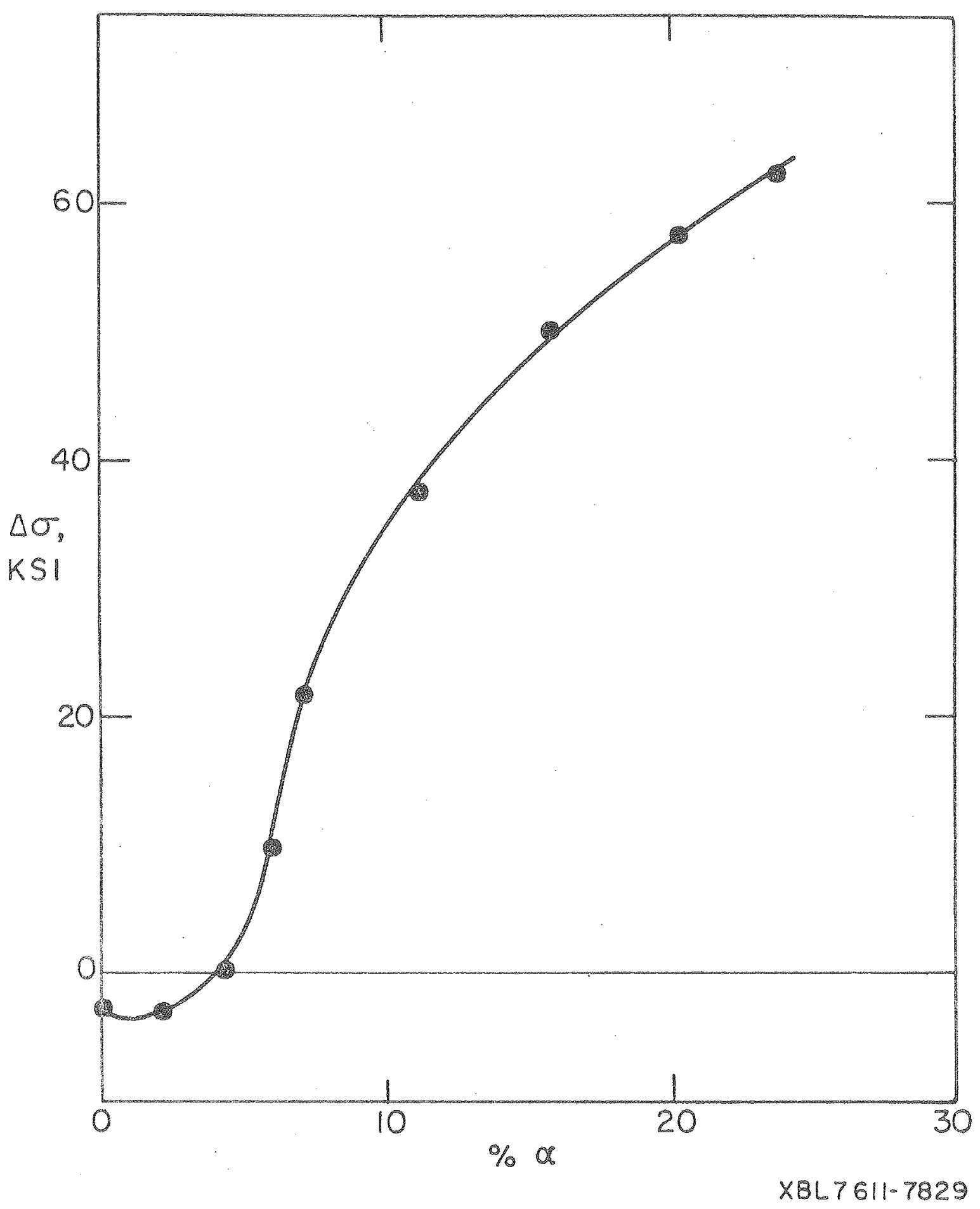

Fig. 9. 
$0+2+30+300$

$\infty 47 \infty$
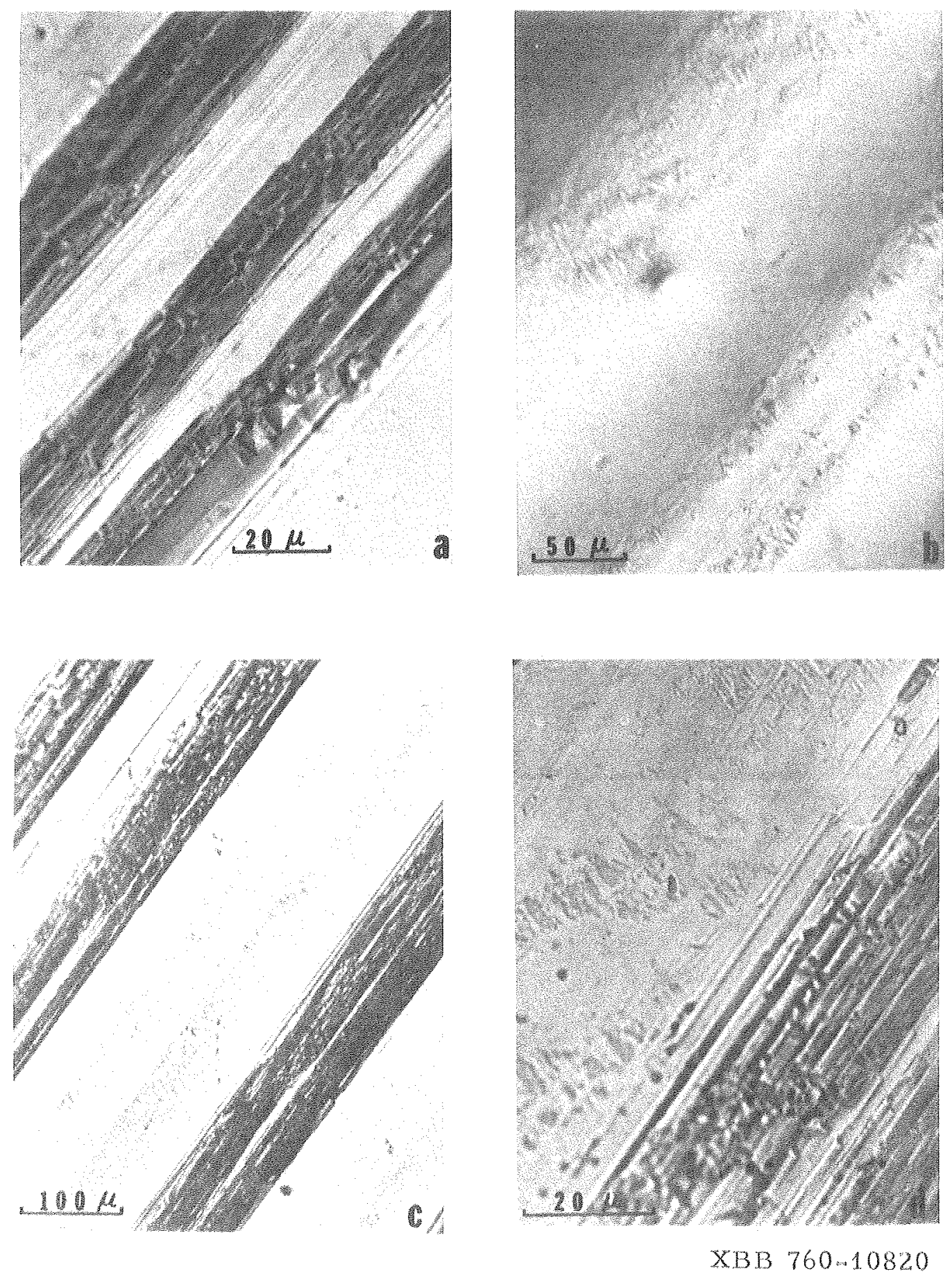

Fig $=10$ 


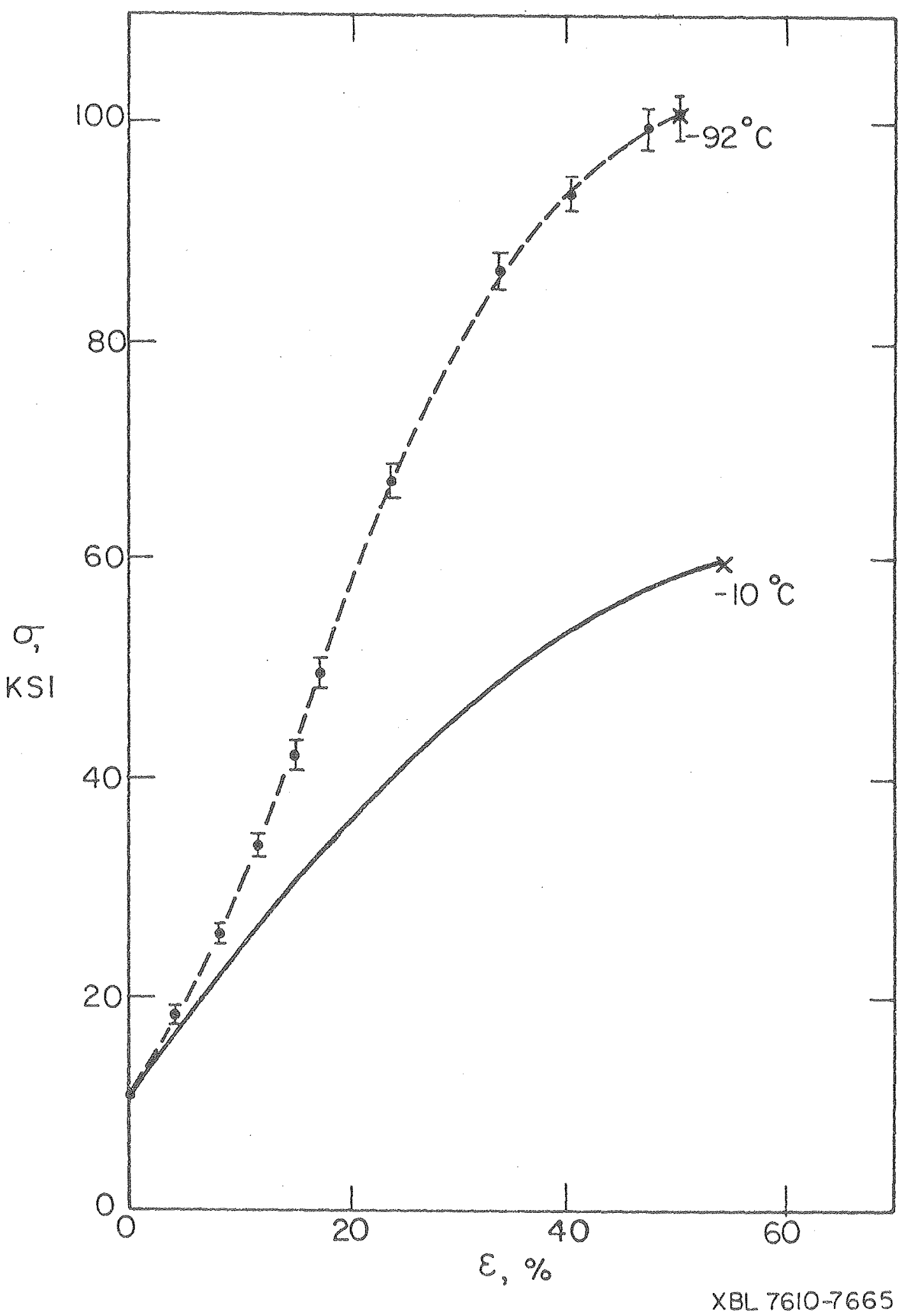

Fig. 11. 
$\begin{array}{llllllllll}1 & 1\end{array}$

$-49$

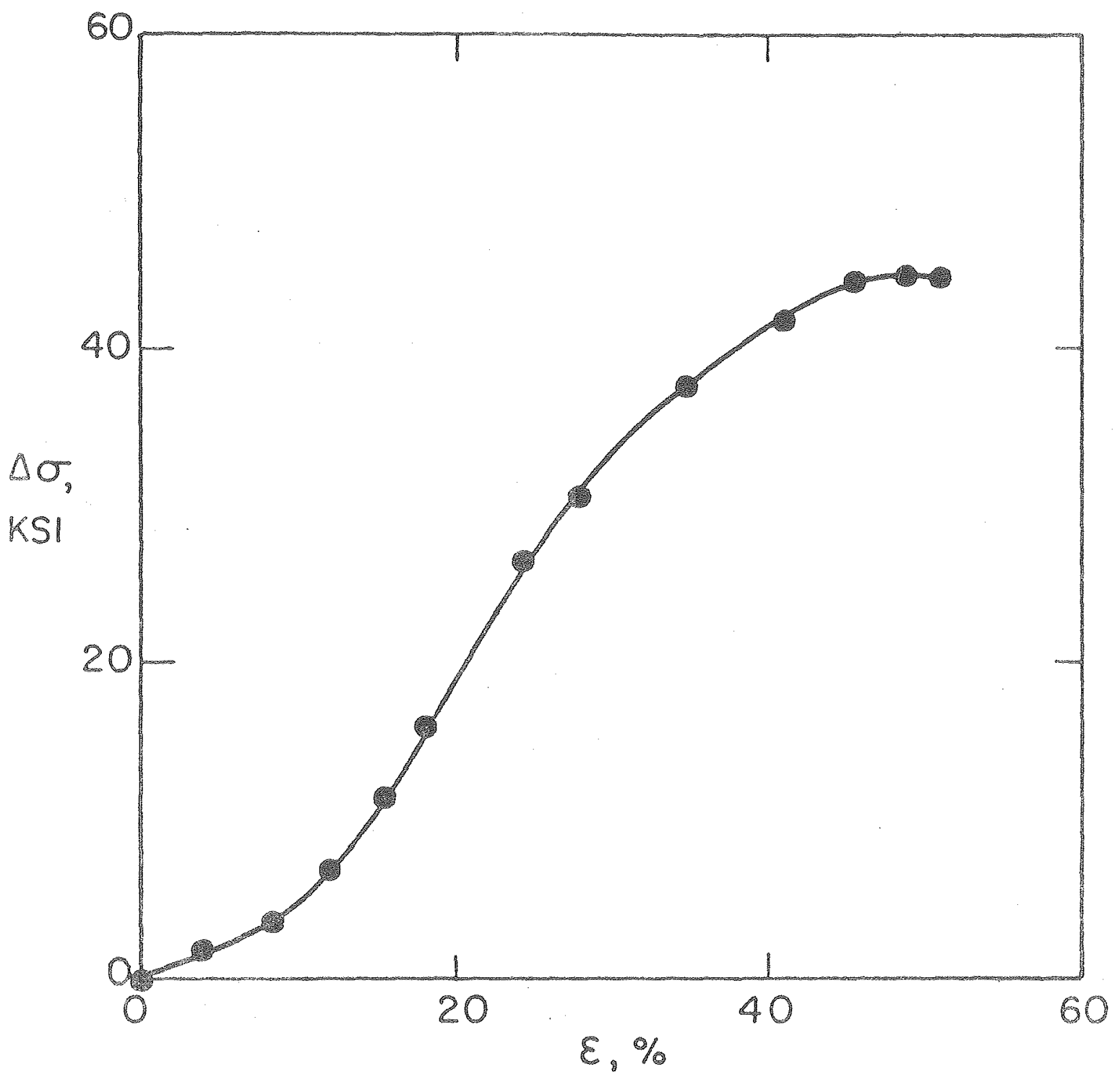

XBL76!1-7827

Fic. 12 . 
$-50-$

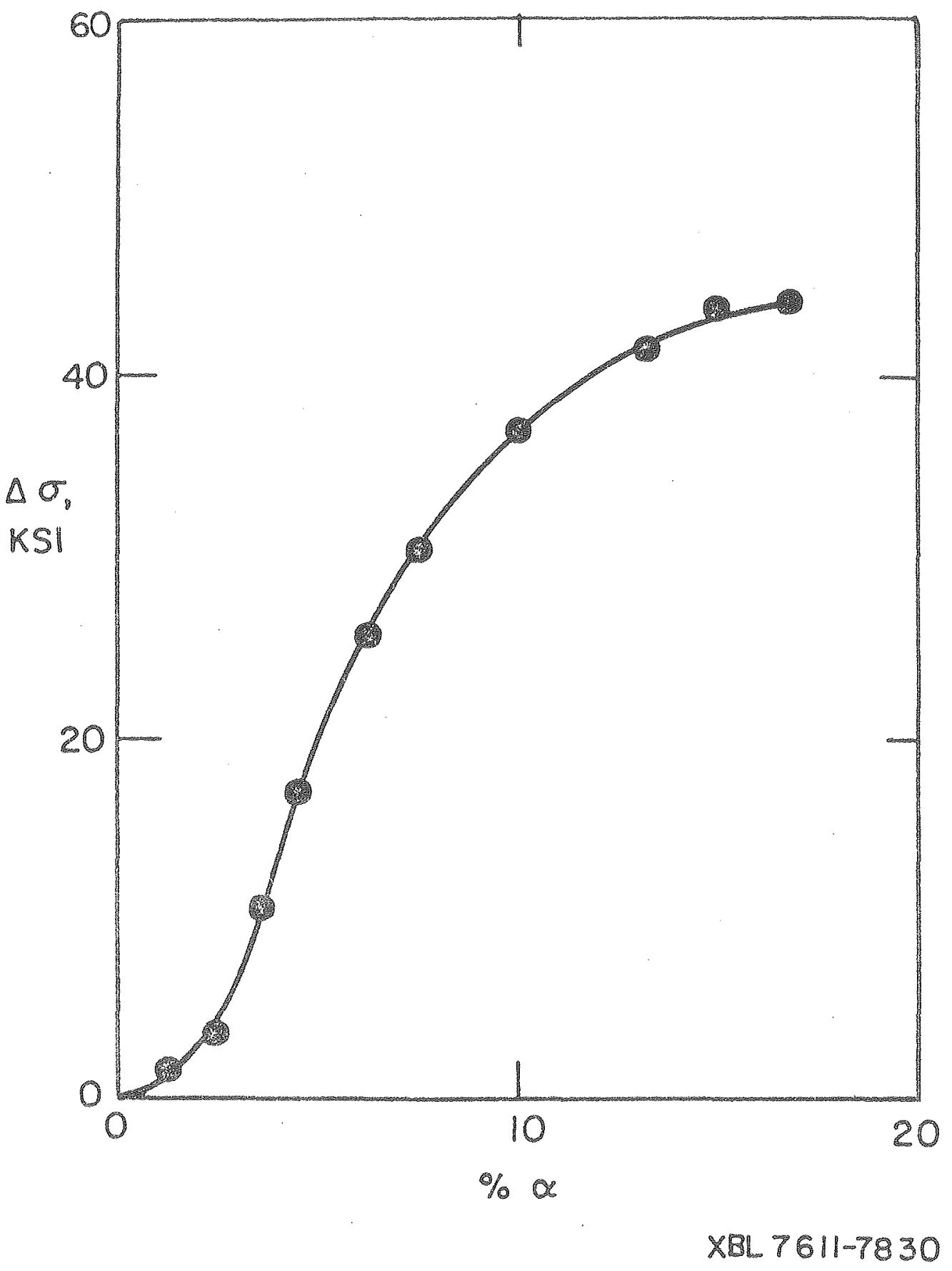

Fig. 13. 
bu

$\ldots 51 \ldots$
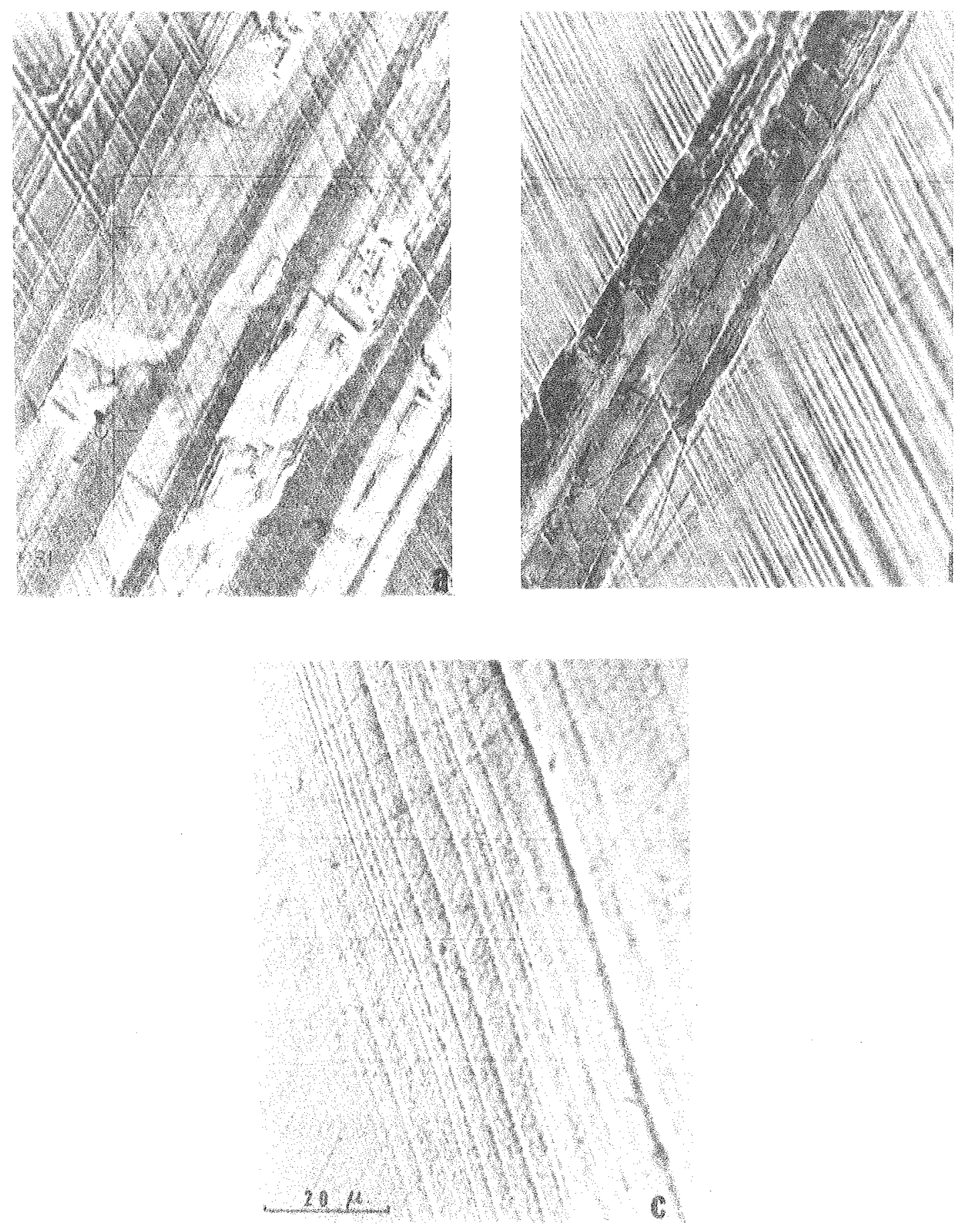

$X B B 760 \times 10822$

Fig: 14 


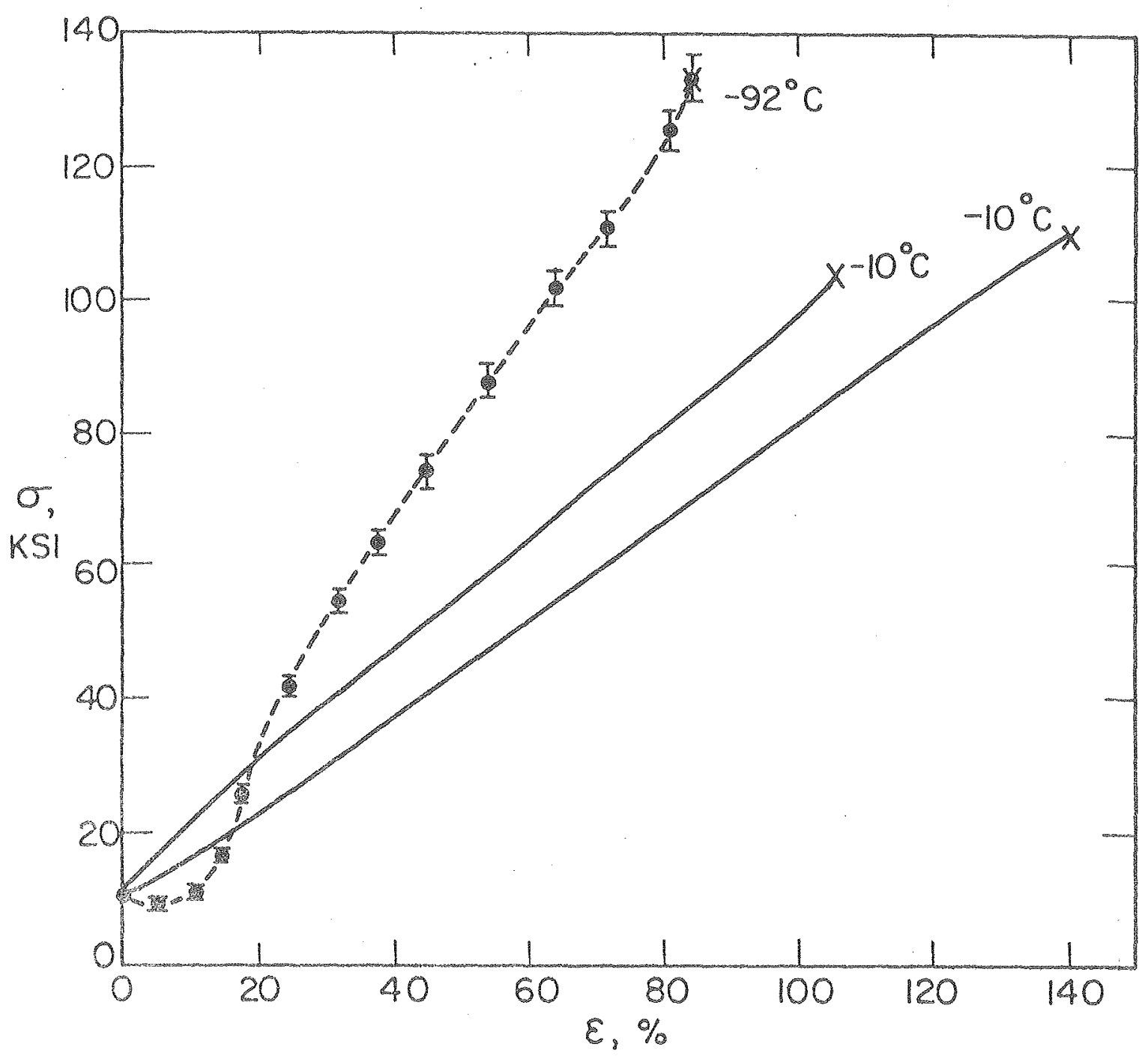

XBL7611-7832

Fig. 15. 


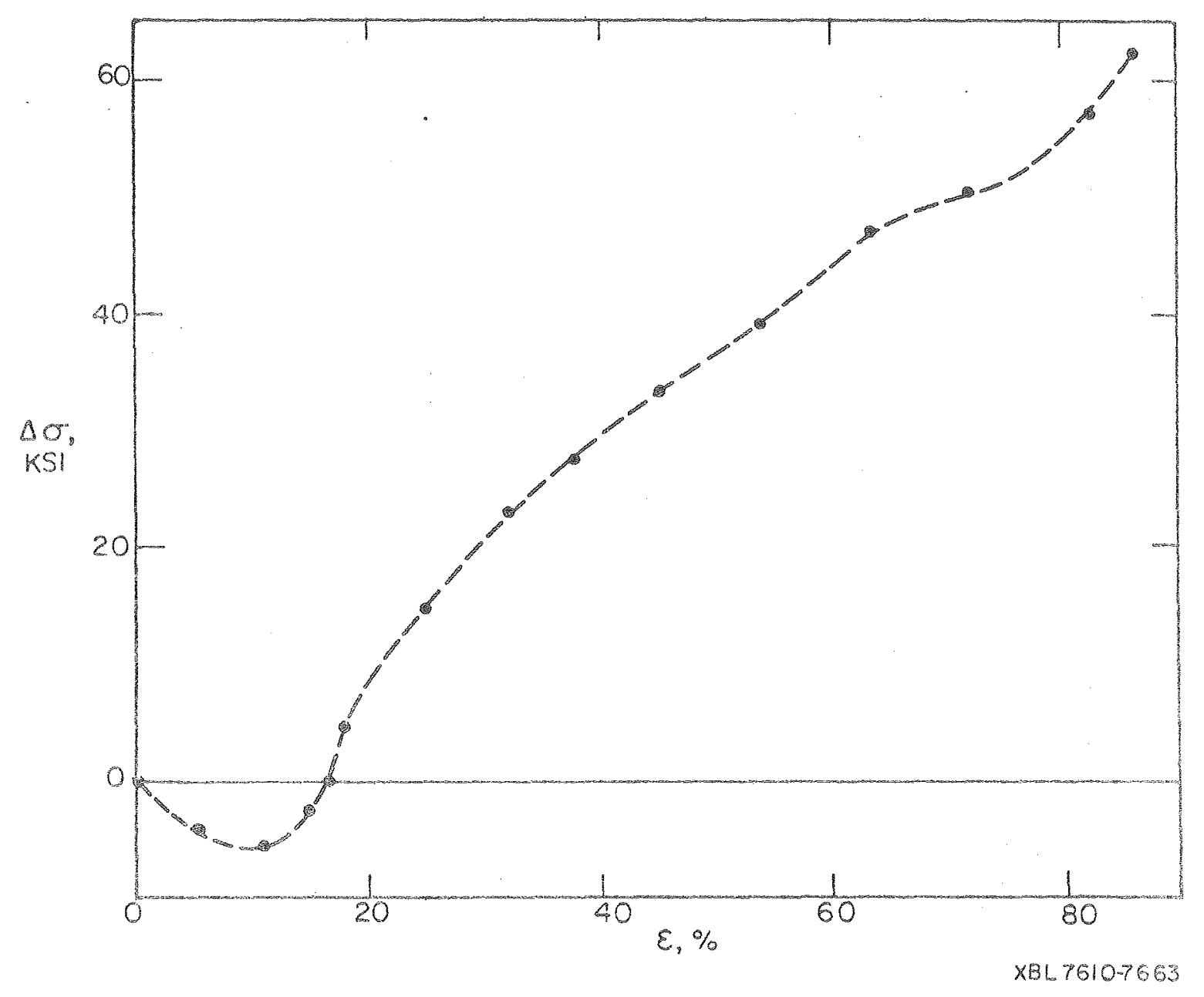

Fig. 16 . 


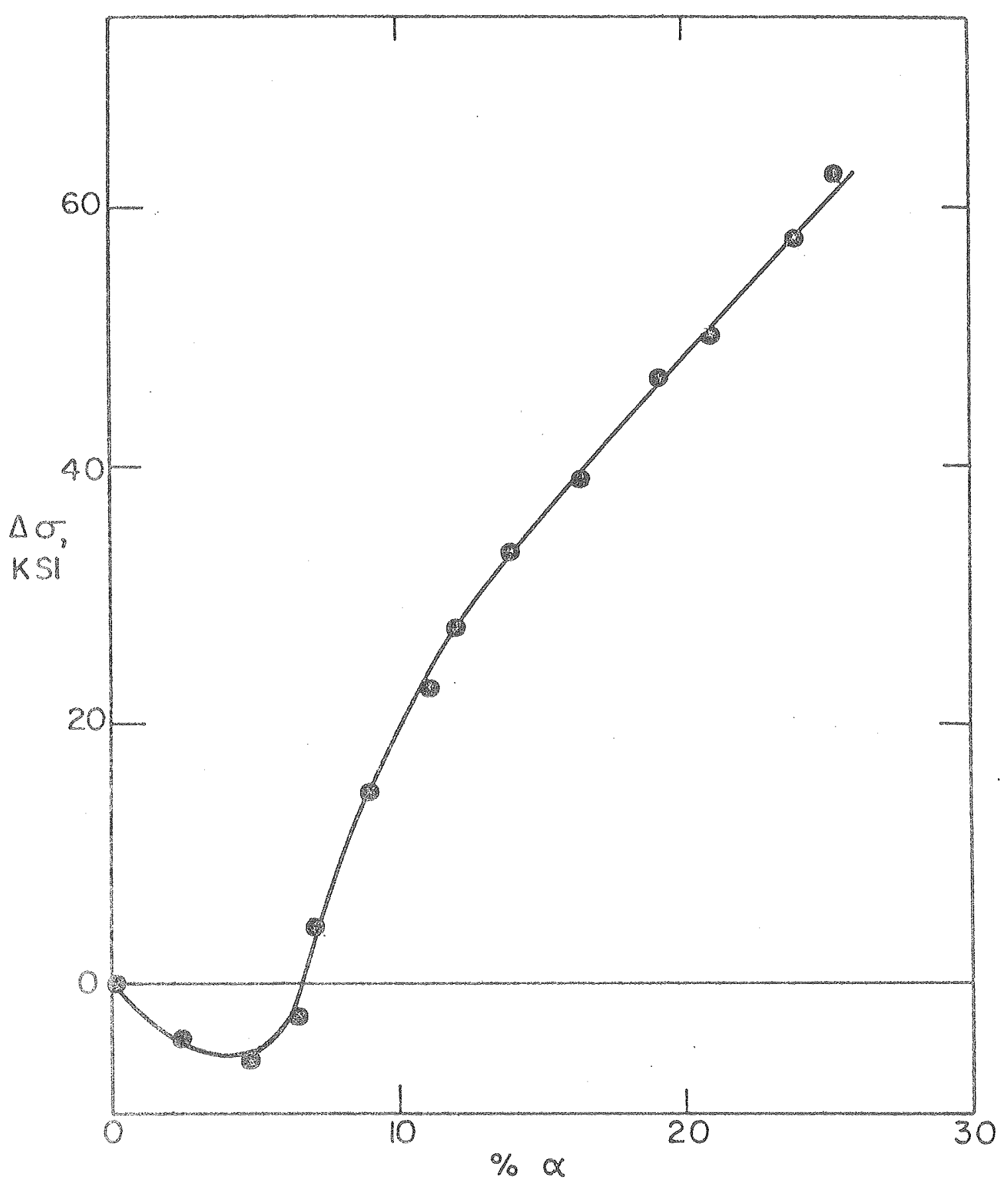

XBL $7611-7828$

Fig. 17 . 


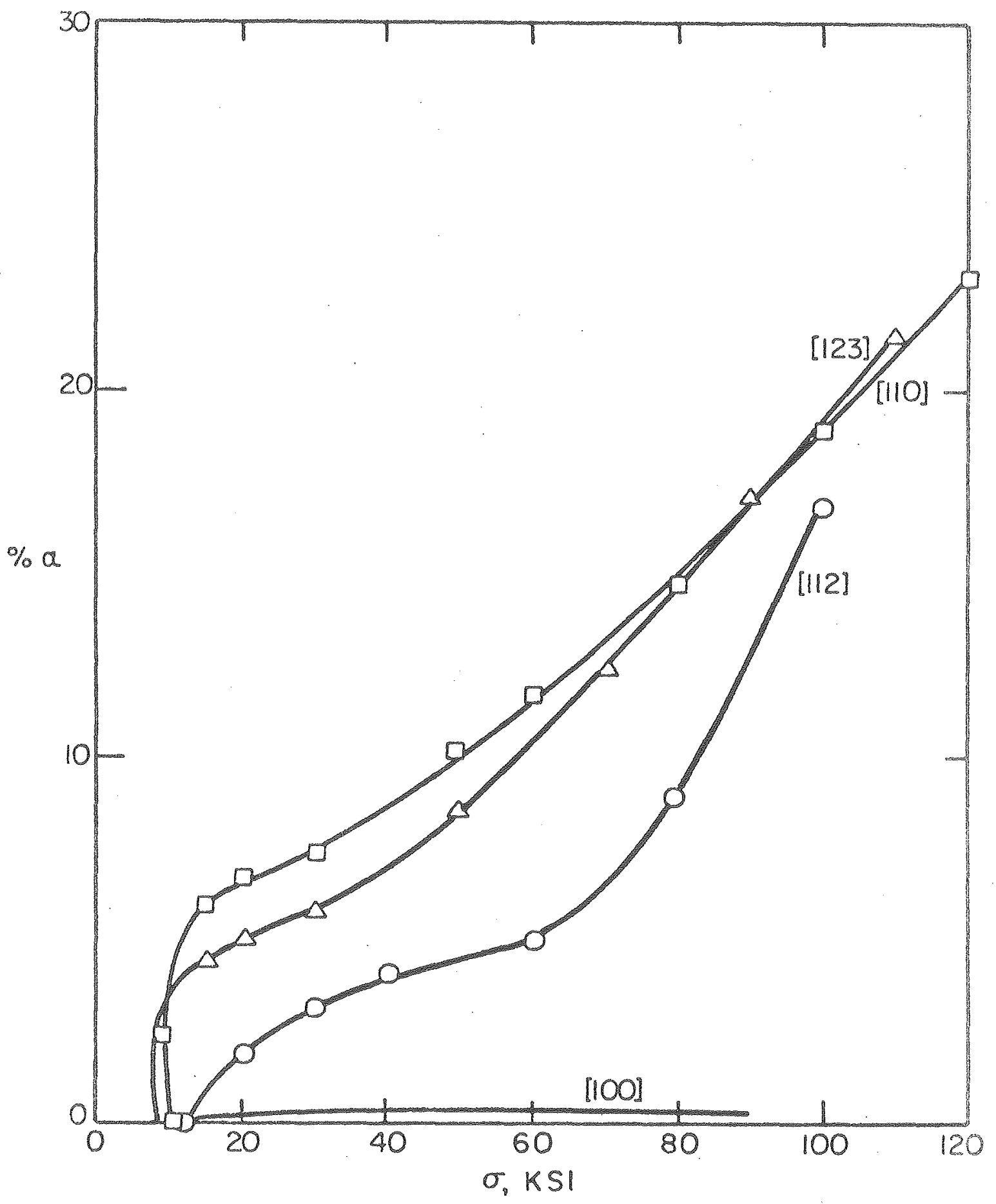

XBL7610-7662

Fig. 18. 
FIGURE CAPTIONS

Fig. I Dendritic pattern of bec martensite locations, observed on (100) face of [110] orientation.

Fig. 2 Side view of [100] tensile specimen, shortly before necking at $\varepsilon_{\mathrm{p}}=.41$.

pig. s Single-crystal tensile specimen.

Fig. 4 Magnetic Measurement Apparatus.

Fig. 5 Strain hardening ourve of [100] specinen, $-92^{\circ} \mathrm{C}$.

Fig. 6 Strain-hardening curves of $-92^{\circ} \mathrm{C}$ and $-10^{\circ} \mathrm{C}[123]$ specimens.

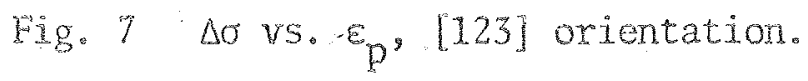

Fig. 8 Vol.* martensite vs plastic strain, all orientations.

Hg. 9 Ao vs. vol. * martensite, [123] orientation.

Fig. 10 a) As-tested surface (\{111\} plane) of a [123] specimen, $\varepsilon_{p}=.06$.

b) Electropolished gage surface, [123] specimen, $\varepsilon_{p}=.06$.

c) [123] specimen gage surface after additional increment of strain following electropolishing of surface.

d) Same as Fig. 10 c) at higher magnification.

Fig. 11 Strain-hardening curves of $-92^{\circ} \mathrm{C}$ and $-10^{\circ} \mathrm{C}[112]$ specimens.

Fig. $12 \wedge \sigma$ vs. $\varepsilon_{p},[112]$ orientation.

Fig. 13 do vs. vol. $-\%, \alpha,[112]$ orientation. 
Fig. 14 Gage surfaces of [112] specimens, showing al1 nontransformation-related slip on one $\{111\}$ plane, a11 transformation on an intersecting $\{111\}$ plane.
a) $-92^{\circ} \mathrm{C}, \varepsilon_{\mathrm{p}}=.20$
b) $-92^{\circ} \mathrm{C}, \varepsilon_{\mathrm{p}}=.20$
c) $-10^{\circ} \mathrm{C}, \varepsilon_{\mathrm{p}}=.54$

Fig. 15 Strain-hardening curves of $-92^{\circ} \mathrm{C}$ and $-10^{\circ} \mathrm{C}$ [110] specimens.

Fig. $16 \Delta \sigma$ VS. $\varepsilon_{p},[110]$ orientation.

Fig. 17 so vs. vol. $-\frac{0}{0} \alpha,[110]$ orientation.

Fig. $18 \%$ a vs. $\sigma$, for al1 $-92^{\circ} \mathrm{C}$ specimens. 
1. Glen Stone, Ph.D. Thesis, Lawrence Berkeley Laboratory Rpt. No. LBL-1800.

2. C.Y. Guntner and R. Reed, Trans. ASi! 55, 399 (1962).

3. K. Hoselitz, Ferromagnetic Properties of Metals and Alloys, Clarendon Press, Oxford, 1952, Chpt. 2.

4. D. Mclean, Mechanical Properties of Metals, John Wiley and Sons, 1962, Chpt. 5.

5. V.F. Zackay, E.R. Parker, D. Fahr, and R. Busch, Trans. ASM 60, $252(1967)$

6. J.F. Breedis and W.D. Robertson, Acta Met. 11, 547 (1963)。

$7.3 . R$. Patel and M.Cohen, Acta Met. 1, 531 (1953).

8. D. Goodchild and W.T. Roberts, Acta Met. 18, 1137 (1970).

9. W. W. Gerbertch, G. Thomas, E.R. Parker, and V.F.Zackay, Proc. of the 2nd Int. Conf. on the Strength of Vetals and Arloys, Asilonar, Calif., 894, Aug. 1970.

10. P.L. Mangonon and G. Thomas, Met. Trans. 1, 1577 (1970). 
This report was done with support from the United States Energy Research and Development Administration. Any conclusions or opinions expressed in this report represent solely those of the author(s) and not necessarily those of The Regents of the University of California, the Lawrence Berkeley Laboratory or the United States Energy Research and Development Administration. 